\title{
تأثير السياسة التجارية على معدل البطالة فى مصر
}

د.وفاء سعد إبراهيم يوسف " دا"

\section{موجز}

تهدف الدراسة إلى تحليل أثر السياسة التجارية في مصر على معدل البطالة في مصر خلال الفترة الزمنية الممتدة

من 1980-2017 من خلال استخدام نموذج انحدار خطى متعدد ، وبالاعتماد على بيانات سلسلة زمنية Series Data

ومن أجل تحقيق هذا الهدف ، تم باختصار عرض السياسة التجارية في الفكر الاقتصادي في أدبيات مختلفة ، مع عرض وتحليل السياسة التجارية المصرية ، كما تم تحليل كل من معدل التعريفة الجمركية والصادرات والواردات المصرية خلال فترة الدراسة. كما تم تتاول مفاهيم معدل البطالة في الفكر الاقتصادي ، ثم عرض وضله وتحليل نتائج القياس.

وتوصلت الدراسة إلى أن هناك تأثير سلبى للسياسة التجارية ، ممثلة في مؤشر الإيرادات الضريبية من التجارة

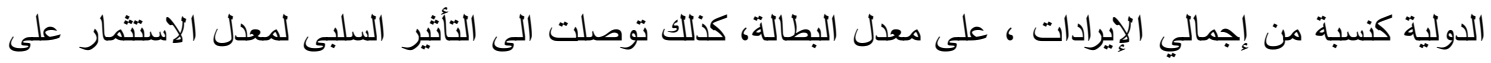

$$
\text { معدل البطالة، مع العلم أن المتغيرات لها معنوية إحصائية. }
$$

\section{The Impact of Trade Policy on the Unemployment Rate In Egypt}

\begin{abstract}
The main objective of this study is to analyze the impact of trade policy on the unemployment rate in Egypt over the period 1980-2017, using a multivariate linear regression model depending on a time series data.

The study explored the trade policy and unemployment in economic thought and different literatures . Furthermore, the study analyzed the evolution of tariff rate, export and imports of Egypt during the period of the study .

The study showed that trade policy affected negatively on unemployment rate. In addition, investment rate had negative impacts on unemployment rate. Noting that the variables have statistical significance.
\end{abstract}


تعتبر السياسة التجارية من أهم السياسات الاقتصادية التى عمل صانعو القرار فى الاقتصاد العالمى على إستخدامها خلال الخمسين السنة السابقة، مما أدى إلى زيادة أهمية التجارة على المستوى الاقتصادى والسياسى على حد سواء، ودفع اقتصاديات الدول لوضع سياسات تجارية تعمل على حماية تجارتها وتقويتها لمواجهة المنافسة العالمية. فمن الملاحظ أن عقد الخمسينيات إلى عقد السبعينيات القرن الماضى كان الإتجاه العام للاقتصاد الدولى هو حماية التجارة من خلال وضع القيود التجارية، وخاصة جانب الواردات لتخفيض العجز فى الميزان التجارى ومن ثم العجز فى ميزان المدفوعات. وفى بداية ثمانينيات القرن الماضى وإلى الآن تم الإتجاه لعدد من الدول خاصة دول جنوب شرق آسيا المعروفة بدول النمور الآسيوية إلى تحرير التجارة، من خلال خفض القيود الجمركية والقيود التجارية على الواردات ومنح الدعم للصادرات، لزيادة الصادرات وتقوية السلع المحلية والحصول على وضع أفضل للمنافسة فى السوق الاقتصادى الدولى. وهناك عدد من الدراسات التى تناولت تأثير السياسة التجارية على أداء الاقتصاد ومنها، (Gozgor)، 2013) التى تتاولت إختبار تأثير الإنفتاح التجارى والعولمة على معدل البطالة فى ملى الدول السبع الكبرى G7 وهى كندا، وفرنسا، والمانيا، وإيطاليا، واليابان، والمملكة المتحدة، والولايات

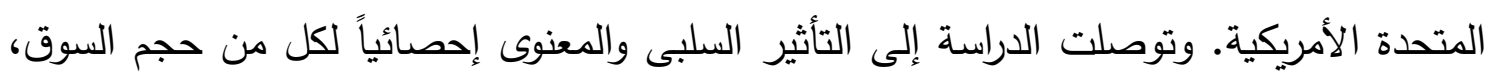
والعولمة، والإنفتاح التجارى على معدل البطالة فى الدول السبع الكبرى(1). كما تتاولت دراسة (Yanikkaya، 2013) إختبار كيف يؤثر تحرير التجارة على معدل النمو فى قطاعات العمل فى الدول النامية والدول المتقدمة. وتوصلت الدراسة إلى أن الإنفتاح التجارى فى شكل أو هيكل التجارة المرتقعة من حيث القيمة لا يؤثر بشكل فعال فى خلق الوظائف فى الدول النامية، ومن ثم لا يؤثر بشكل كبير على خفض معدل البطالة، بالإضافة إلى أن التجارة

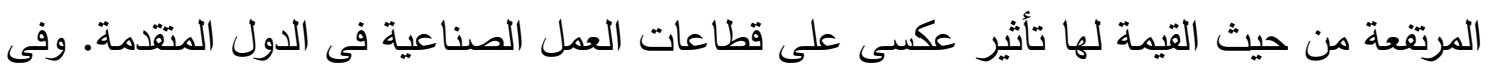
المقابل لها تأثير إيجابى على العمل فى قطاعات الصناعة والخدمات فى الدول النامية، ومن ثم توفير فرص العمل وخفض معدل البطالة(2). 
كما إستخدمت دراسة (Nwaka, at.el، السياسة التجارية على معدل البطالة فى نيجيريا. وتوصلت الدراسة لوجود علاقة بين السياسة التجارية ومعدل البطالة فى الأجل الطويل، حيث الزيادة فى الناتج الحقيقى ومستوى الدخل الفردى الناتج من إنشاء المشروعات وفتح الأبواب أمام المستثرين وإلغاء القيود يؤدى بدوره إلى خفض معدل البطالة فى الأجل الطويل (3). بالإضافة إلى دراسة (Warrad، 2017) والتى تتاولت تأثير الإنفتاح التجارى على معدل البطالة فى الدول العربية وهى الجزائر، والبحرين، ومصر ، والأردن، وعمان، والسعودية، وتونس خلال الفترة الزمنية (1990-2015). وتوصلت الدراسة إلى التأثير السلبى للإنفتاح التجارى على معدل البطالة، حيث كلما زادت الدولة من إتجاهها نحو الإنفتاح أدى ذللك لإنشاء المزيد من المشروعات التى تعمل على خلق فرص عمل، ومن ثم خفض معدل البطالة، بالإضافة إلى إرتفاع فى معدل النمو الاقتصادى(4). كذلك تهدف دراسة (Zaki and Salem، 2017) إلى إختبار تأثير الإنفتاح التجارى على العمل خاصة على قوة العمل فى القطاعات غير الرسمية وقطاعات العمل المؤقتة ذات العقود الأقل من 12 شهر من إجمالى القوة العاملة فى مصر خلال الفترة الزمنية (1998-2012) بإستخدام بيانات مجمعة Panel Survey. والتى شهدت عدة تغيرات فى قطاع العمل فى تلك الفترة خاصة خلال الأحداث السياسة التى شهدتها مصر ، وتأثير ذلك على الصادرات والإنتاجية وقواعد العمل. وتوصلت الدراسة إلى التأثير الإيجابى للإنفتاح التجارى (التى يمثلها التعريفة الجمركية) على قطاعات العمل غير الرسمية وقطاعات العمل ذات العقود المؤقتة(5). وتستمد الدراسة الحالية أهميتها فى كونها لا تركز فقط على حرية السياسة التجارية والإنفتاح التجارى، بل تهتم وتركز على السياسة التجارية كسياسة اقتصادية للدولة لفترة زمنية طويلة نسبياً. لتمر بمرحلة حماية التجارة إلى مرحلة حرية التجارة، بإستخدام مؤشر حصيلة الإيرادات الضريبية من التجارة الدولية نسبة من إجمالى الإيراد الكلى للدولة. ومن ثم تتمثل مشكلة الدراسة فى إرتفاع معدل البطالة فى مصر خاصة فى الفترة الأخيرة التى تلت الثورة المصرية فى عام 2011، مما استدعى صانع القرار إستخدام السياسات 
الاقتصادية لمحاولة خلق فرص العمل وزيادة الإنتاج. وتمثل السياسة التجارية أهم الأدوات التى تعمل مصر على استخدامها لفتح السوق المصرى، والحصول على حصة من السوق العالمى. بالإضافة إلى عقد المعاهدات والإتفاقيات التى ينص بعضها على إقامة مشروعات إستثمارية فى مصر لخلق فرص عمل وزيادة الإنتاج، ومن ثم خفض معدل البطالة. كما تقوم هذه الدراسة على فرضية أساسية: وهى "هناك تأثير للسياسة التجارية على معدل البطالة فى مصر". وتهدف هذه الدراسة إلى إختبار مدى صحة أو خطأ الفرضية الأساسية، بجانب دراسة السياسة التجارية فى مصر خلال فترة الدراسة والتى تمثل أحد أهم الأدوات أمام مصر للدخول إلى مدى السوق العالمى، وزيادة التعاملات التجارية وعقد الإتفاقيات والمعاهدات التجارية، بغرض زيادة المشروعات الإستثمارية والإنتاجية لخلق فرص العمل، ومن ثم خفض معدل البطالة. وفى سبيل تحقيق هذا الهدف تعتمد الدراسة على الأسلوب الوصفى فى عرض الإطار النظرى للسياسة التجارية وعرض السياسة التجارية فى مصر وتحليل كل من معدل التعريفة الجمركية والصادرات والواردات المصرية خلال فترة الدراسة، بالإضافة إلى عرض البطالة فى الفكر الاقتصادى، بجانب

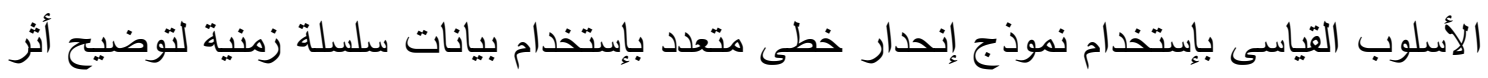
السياسة التجارية على معدل البطالة فى مصر خلال فترة الدراسة (1980-2017). وتتقسم الدراسة إلى خمسة أقسام بخلاف المقدمة، القسم الأول يتناول الإطار النظرى للسياسة التجارية فى الفكر الاقتصادي ، ويتناول القسم الثانى تحليل السياسة التجارية فى مصر، ويلقى القسم الثالث الأضواء على انعكاسات السياسة التجارية فى مصر على كل من معدل التعريفة الجمركية والصادرات والواردات المصرية خلال فترة الدراسة، أما القسم الرابع فيوضح البطالة فى الفكر الاقتصادى، ويختص القسم الخامس بتوصيف النموذج القياسى وتحليل النتائج. وضضم القسم الأخير الخلاصة وأهم نتائج وتوصيات الدراسة. 
أولاً : السياسة التجارية فى الفكر الاقتصادى

تعتبر السياسة التجارية من بين السياسات الاقتصادية التى تعطى للدولة حق المشاركة فى العلاقات الاقتصادية الدولية. والتى تعتبر من أهم ركائز وأدوات السياسة الاقتصادية منذ القدم والتى تتضمن قواعد وتشريعات رسمية مصدق عليها من طرف الدولة التى ترتبط بينها تجارياً وذلك بتقييد أو تحرير التجارة حسب ظروف كل دولة. كما أنها جزء لا يتجزأ من السياسة الاقتصادية المطبقة فى مجال التجارة الدولية، حيث تعتبر السياسة التجارية تلك السياسات التى تتبعها الدولة فى مجال التجارة الخارجية بغرض التأثير على الصادرات والواردات، كما تلجأ الحكومات إلى وضع السياسات التجارية بهدف معالجة الإختلال فى ميزان المدفوعات. كذلك تعرف السياسة التجارية بإنها مجموعة الإجراءات والتدابير المتخذة من قبل الدول فى إلى نطاق علاقتها الاقتصادية مع الدول الآخرى فى مجال الإستيراد والتصدير بصفة أساسية، حيث يتم إستخدام السياسة التجاريـة كأداة للتنويع الصناعى وخلق القيمة المضافة. كما أنها مجموعة الأساليب والأدوات التى تتخذها الدولة للحد من الواردات أو لتشجيع الصادرات(6). لذلك فإن السياسة التجارية تتعلق بإدارة التجارة الخارجية للدولة والتى تؤثر على جميع المتغيرات الاقتصادية الكلية مثل، الناتج المحلى الإجمالى، والإستثار، ومعدل التضخم، ومعدل البطالة. ومن ثم يمكن القول بأن السياسات التجارية تتواجد فى الاقتصاديات المفتوحة التى تقيم علاقات اقتصادية مع العالم الخارجى ولا توجد فى الاقتصاديات المغلقة(7). ومن خلال التعريفات السابقة يتضح أن السياسة التجارية هى سياسة اقتصادية مطبقة فى مجال التجارة الدولية عن طريق التأثير على الصادرات والواردات بغية تحقيق أهداف اقتصادية معينة. كما أن التطور الاقتصادى الذى شهدته الدول المختلفة أدى إلى تطور السياسات التجارية التى إتبعتها هذه الدول منذ عهد التجاريين وحتى الآن. حيث أن كل مرحلة تتطلب توازن قوانين ونظم وإجراءات معينة لتنظيم تجارتها الخارجية حسب متطلبات المرحلة وإحتياجاتها وحسب النظام الاقتصادى الذى تتبعه كل دولة. فمن الملاحظ أن المذهب التجارى هم أول من إتبعو السياسات التجارية حيث تبلور هذا المذهب وأهميته فى أواخر القرن السابع عشر وإستمر بالإزدهار حتى أوائل القرن الثامن عشر • وإعتمدت الفكرة الأساسية للتجارين فى أن الدولة يجب عليها أن تستخدم 
كل قوتها وصلاحياتها من أجل تحقيق النفع العام، لذلك كان يعتبر الحياة الاقتصادية والسياسية على أنهما أدوات وآليات يستطيع من خلالها صانع القرار أن يحقق الكفاءة والعدالة المطلوبة من خلال وضع القوانين وإستخدام الأجهزة العامة بشكل كفه، ومن ثم فإن القوانين التى تضعها الدولة لتنظيم الدولة كل من النشاط التجارى والزراعى والصناعى يمكن أن تحقق نتائج أكثر فاعلية عن تللك التى وضعتها المحاولات الفردية(8).

ويتبنى المذهب التجارى سياسات عدائية ، وهى سياسة إفقار الدول الأخرى أو سياسة

إفقار الجار ، وتتص على أن ربح الدولة قائم على خسارة الدولة الأخرى وذلك عن طريق تحقيق أكبر قدر من الثروة عن طريق تدفق الذهب وتراكمه وتحقيق فائض فى الميزان التجارى. ولإستمرار تحقيق ذلك تتخذ الدولة كافة إجراءات السياسة التجارية والتى من أهمها فرض الضرائب على الواردات، وزيادة الدعم للصادرات، بالإضافة إلى الرقابة على سعر الصرف، والتدخل فى آليات السوق والرقابة على الأسعار والأجور وزيادة الإحتكار ليزداد ربح طبقة التجار، حيث هى الطبقة المسئولة فى المذهب التجارى عن زيادة ثروة الدولة وقوة نفوذها. ومن ثم يعمل المذهب التجارى نحو الحماية وليس الحرية التجارية. وبعكس المذهب التجارى إهتمام المذهب الطبيعى بالحرية الاقتصادية والإعتماد على فكرة التوازن التلقائى وعدم التدخل فى الحياة الاقتصادية، حيث كل ما يجرى فى الدولة هو بالقانون الطبيعى الذى يعمل على تصحيح الإختلال دون التدخل من الأفراد فى صورة الدولة. لذلك إنصب إهتمام المذهب الطبيعى على النشاط الزراعى لأنه يمثل الإنتاج الطبيعى من دون التدخل من قبل الأفراد، ولم يعطى الإهتمام الملائم لكل من النشاط الصناعى والنشاط التجارى. كذلك لم يهتم بفرض الضرائب كوسيلة للحصول على الإيرادات حيث تتمثل قوة الدولة فى الناتج الصافى للدولة وليس بما تملكه الدولة من ذهب وفضة، من ثم لم تلقى السياسة التجارية إهتمام كبير من قبل المذهب الطبيعى (9) أما المذهب الكلاسيكى فقد عارض بشدة فكرة التذخل فى الشئون الاقتصادية والتدخل فى آليات السوق بواسطة السياسات التجارية وفكرة زيادة الصادرات وخفض الواردات من خلال زيادة 
التعريفة الجمركية. وأن السياسات الحمائية والتدخل فى الإنتاج والتوزيع وتحديد الأسعار وفرض الضرائب المتعسفة ووضع القيود الجمركية، كل ذلك يعمل على تشوه السوق وزيادة عرض النقود

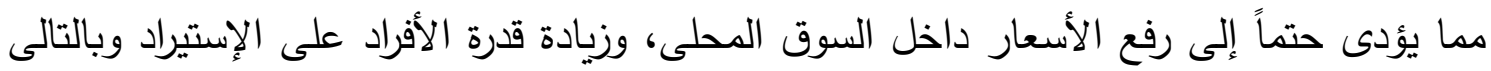
تحول الفائض فى ميزان المدفوعات والذى يعتبر حجة التدخل وإستخدام السياسات الحمائية إلى الى عجز فى ميزان المدفوعات.

ومن ثم إعتمد بشكل أساسى على فكرة الحرية الاقتصادية ومن ضمنها، حرية النشاط التجارى، وعدم فرض الضرائب على الواردات لزيادة التبادل التجارى بين الدول، كذلك فكرة

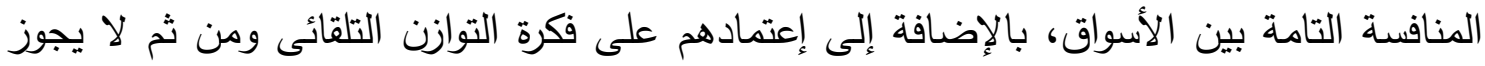

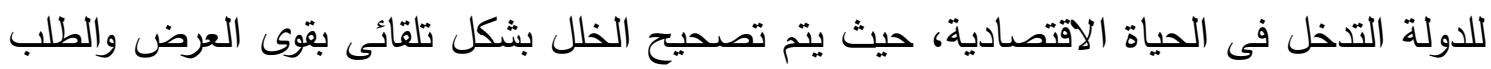

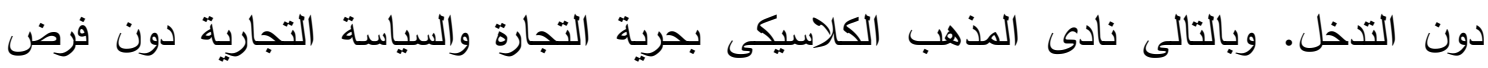
قيود (10).

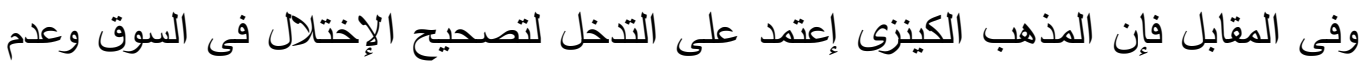

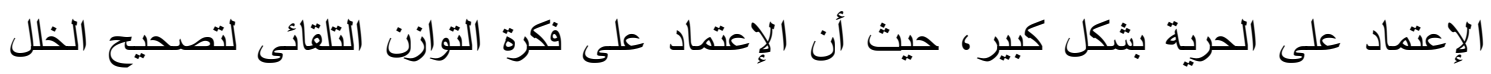

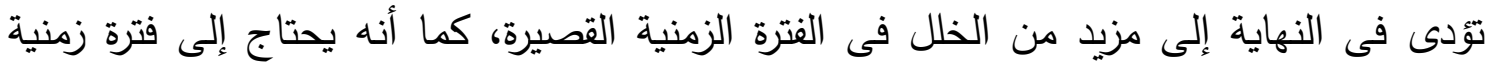
طويلة قد تؤدى فى النهاية لمزيد من الإضرار. لذللك دافع كينز عن السياسات الحمائية والتتخل

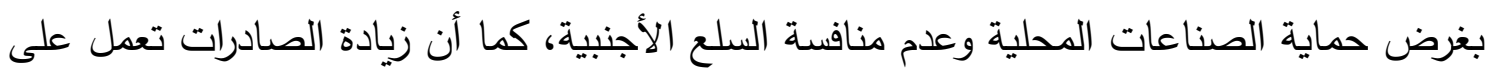

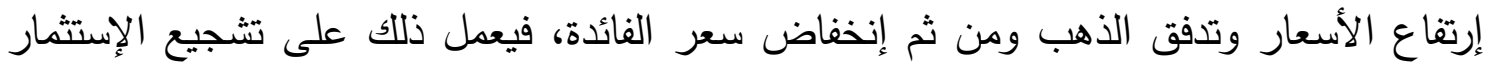
نتيجة زيادة المعروض من النقود، وبالتالى زيادة خلق فرص العمل. وهو ما يهدف اليه المذهب الإنب الكينزى (11).

ومن ثم إعتمد الدذهب الكينزى على تدخل الدولة بالسياسة المالية حيث تعتبر أكثر كفاءة

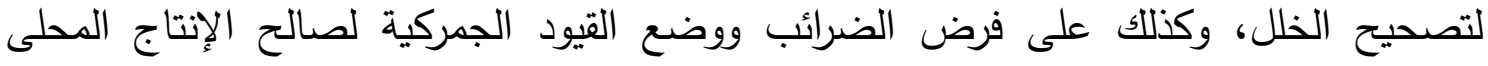
وحماية المنتجات المحلية من المنافسة الأجنبية. ومن ثم إتجه المذهب الكينزى نحو الحماية وليس حرية التجارة، وبهذا تعتبر السياسة التجارية سياسة حمائية. 
وينحصر الإهتمام بالسياسة التجارية فى الدول النامية بالإتجاه إلى الحماية وتقييد التجارة بالإعتماد على عدد من التبريرات منها، تحسين معدل التبادل التجارى حيث أن فرض قيود جمركية سيؤدى إلى رفع أسعار السلع المستوردة، مما يؤدى بدوره إلى خفض الطلب عليها محلياً وبالتالى ينخفض سعرها فى السوق الدولى، ومن ثم سيكون له آثار إيجابية على معدل التبادل التجارى. كذلك حماية الصناعات الوليدة وهو تبرير قديم يستخدم من قبل الدول النامية كحجة قوية لفرض القيود الجمركية، حيث أن الصناعات فى أولى مراحل تكوينها تكون مرتفعة التكاليف وإلى أن تصل المنشأة الصناعية إلى حجمها الأمثل وتتمتع بوفرات الحجم، فإنها تكون فى حاجة إلى حماية من المنافسه الأجنبية. لذلك يجب فرض قيود جمركية لفترة زمنية معينة تستطيع من خلالها الصناعة الوليدة النمو واكتساب القدرة على منافسة السلع المستوردة(12). وتتحصر طريقة الدول النامية فى تطبيق الحماية بعدد من الأدوات الأكثر إنتشاراً وتطبيقاً وهى، التعريفة الجمركية، وتعتبر من أكثر الأدوات السياسة التجارية تطبيقاً فى الدول النامية لسهولة تطبيقها لرفع سعر السلع المستوردة لحماية السلع المحلية بالإضافة إلى زيادة حصيلتها الإيرادية. ويتم فرضها إما بمبلغ معين على السلع المستوردة وتسمى تعريفة نوعية، أو بنسبة دن سعر السلعة المستوردة وتسمى تعريفة قيمية، وفى بعض الأحيان يتم فرض الأثنين معاً تحت مسمى التعريفة المركبة. وهناك عدد من المناهج المتاحة للدول التى تعيد صياغة سياساتها التجارية للإستفادة القصوى منها، وزيادة الرفاهية الاقتصادية وزيادة معدلات النمو الاقتصادى، ومن تللك المناهج، منهج إعادة الهيكلة من جانب واحد Unilateral Reforms، منهج الإتفاقيات أو الإرتباطات الخارجية External Engagement، منهج المناهج الإقليمية Regional Approaches (13). ثانياً : تطور السياسة التجارية فى مصر تعتبر مصر من أولى الدول العربية التى نقلت إتجاه سياساتها التجارية من إتجاه الحماية إلى الحرية، فبعد حصول مصر على إستقلالها السياسى إتجهت مصر فى سياساتها التجارية لإستراتيجية ذات توجه داخلى بإستخدام سياسة الإحلال محل الواردات وحماية الصناعات الوليدة، من خلال الإهتمام بالصناعة المحلية ووضع تعريفة جمركية على السلع المستوردة لتشجيع 
الصناعة المحلية ذات التكلفة العالية. ومن ثم إرتفاع سعر السلع المستوردة لتساوى مع سعر السلع المحلية لتواجه السلع المحلية حالة تنافس شبه متوازن مع الصناعة المستوردة، إلا أن تلك الإستراتيجية أثبتت فشلها حيث إعتمد المنتجين المحليين على دعم الدولة لحماية الصناعة الوليدة دون العمل على تحسين جودة السلعة لتصل إلى قوة السلع المستوردة. وفى المقابل لم تعمل الدولة على سحب دعمها من المنتجين لتحفيزهم على التحسين وإنخفاض التكلفة. بالإضافة إلى عدم إحلال السلع الوسيطة المستخدمة فى الإنتاج مثل الآلآت، وبالتالى إستمر الإستيراد من الخارج ولكن بفروق أسعار مرتفعة وكبيرة نتيجة التعريفة الجمركية المفروضة على الإستيراد، مما أدى الإى بدوره إلى المزيد من إرتفاع الواردات والمزيد من عجز فى ميزان المدفوعات(14). وإستمر الحال على ذلك منذ الإستقلال إلى عقد السبعينيات إلى أن تم التحول من الإستراتيجية ذات التوجه الداخلى بإستخدام سياسة الإحلال محل الواردات إلى إستراتيجية ذات توجه خارجى بإستخدام سياسة الإنتاج من أجل التصدير، والتى أثثتت كفاءتها فى دول النمور الآسيوية. وأول خطوات التحول إنضمام مصر إلى الإتفاقية العامة للتعريفات والتجارة المعروفة بإسم الجات فى عام 1970 لتحصل على المعاملة التفضيلية للدول النامية التى تتص على إستمرار فرض القيود التجارية على الواردات لتشجيع الصناعات المصرية ذات الميزة النسبية مثل المنسوجات، مع العمل على تخفيض تدريجى نحو الإلغاء الكامل لتلك القيود حتى تصبح الصناعة المصرية ذات قوة لمواجهة المنافسة الدولية. لذلك عملت مصر فى فترة الثمانينيات وأوائل التسعينيات على الإتجاه نحو مزيج من الحرية والحماية التجارية، فهناك سلع عملت على إلغاء القيود الجمركية عليها وسلع آخرى عملت على فرض قيود جمركية عليها لحماية المنتجات المحلية، مع البدء فى وضع والدخول لبعض الإتفاقيات التجارية ومن أهمها إتفاقيات التعاون الثامل مع دول الأوروبية فى الثمانيات. ومع إنضمام مصر إلى منظمة التجارة العالمية فى 1995 عملت مصر على الإلغاء الكامل فى بعض القطاعات للقيود الجمركية والإلغاء التدريجى للقيود الجمركية، مع إتجاه السياسة التجارية نحو الحرية وعقد العديد من الإتفاقيات التجارية مثل، إنضمام مصر إلى السوق المشتركة المعروفة بالكوميسا فى عام 1999، وإتفاقيات الشراكة المصرية الأوروبية فى عام 2004، وإتفاقية الأغادير 
فى عام 2004، كذلك إتفاق خطة العمل أو كما تعرف بسياسة دول الجوار مع الاتحاد الأوروبى

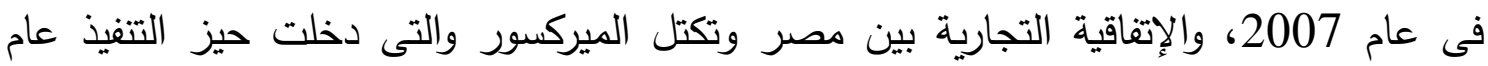

ويوضح الجدول (م-1) فى الملحق الإحصائى معدل التعريفة الجمركية على جميع المنتجات بالأوساط المرجحة كنسبة مئوية خلا الفترة (1995-2017)، والتى توضح فتحلى فترة الإنتقال من الحماية الجزئية إلى الحرية الكاملة بشكل تدريجى. وقد بلغ معدل التعريفة 17.5 بالها فى عام 1995 ثم بدأت فى الإنخفاض التدريجى لتصل إلى 14.7 \% فى عام 1998 1998، وإرتفعت

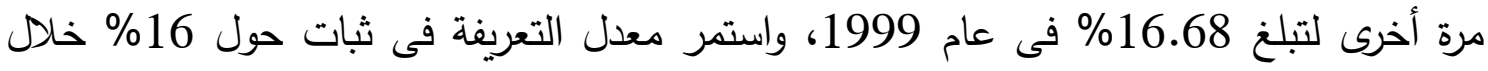

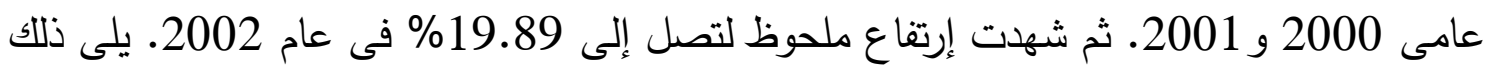

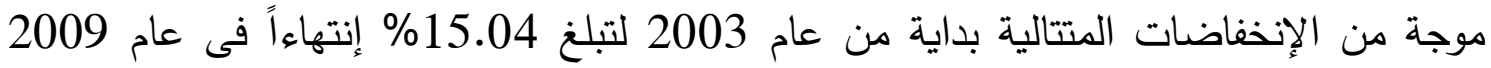
لتبلغ 8.26\%، ما عدا عام 2006 حيث بلغ معدل التعريفة 10.05\%. ثم استقر معدل التعريفة

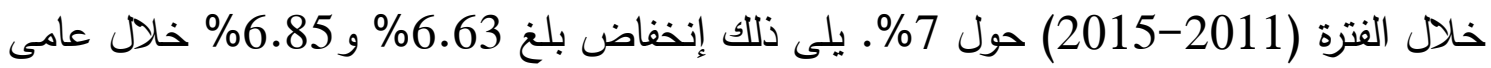
2016 و 2017 على التوالى. ( شكل رقم 1) ويتضح من التحليل السابق أن الإتجاه العام لمعدل التعريفة هو الإنخفاض تطبيقاً لإتجاه

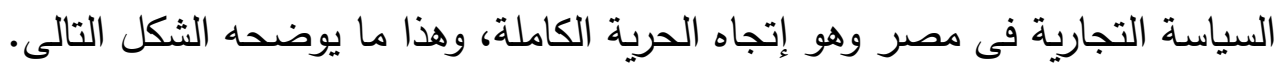

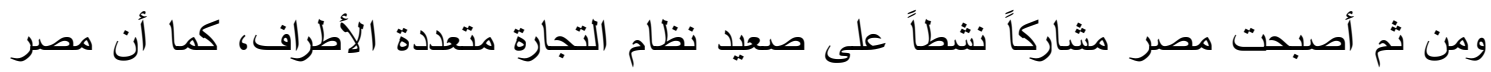

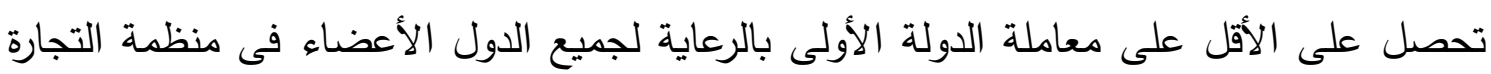

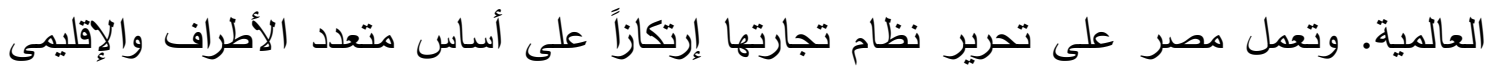

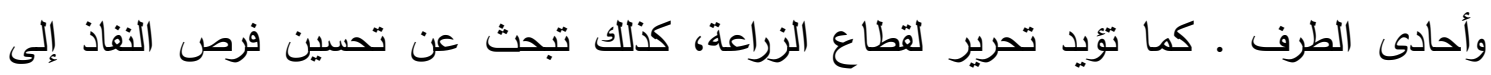

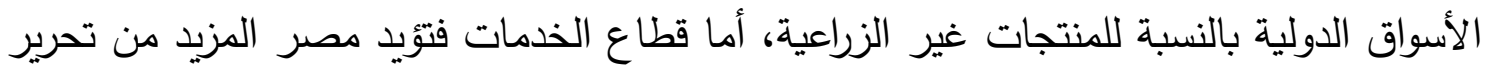

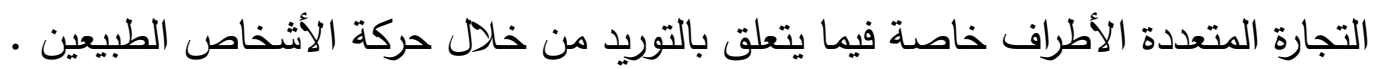




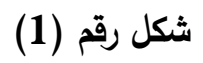

تطور معدل التعريفة الجمركية فى مصر خلال الفترة (1995-2017)

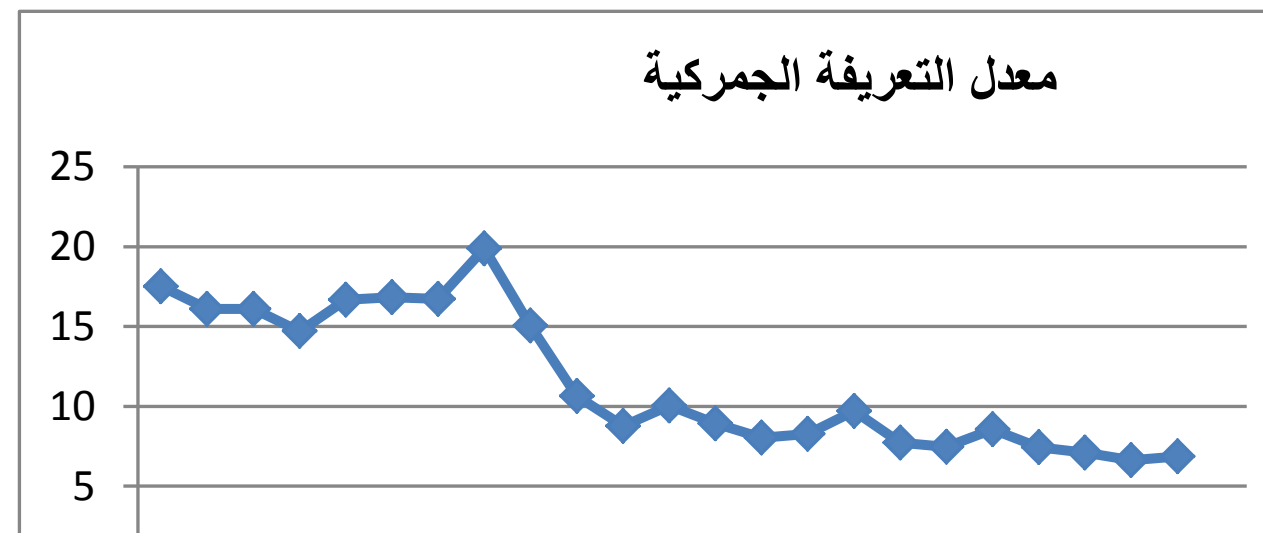

المصدر: www.worldbank/data.org.

بالإضافة إلى قانون الإستثمار الجديد الذى يشجع على الإستثمار وفتح المزيد من

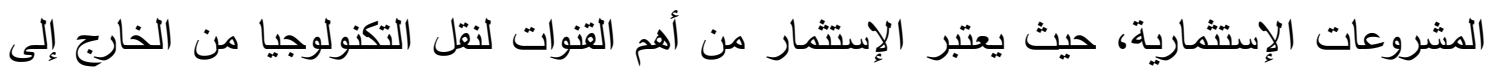

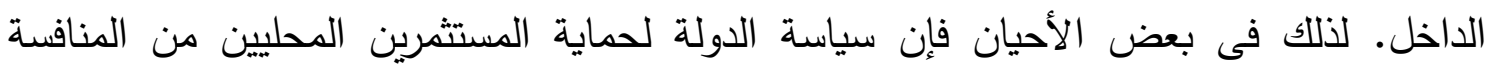
الأجنبية لفترة زمنية مؤقتة أفضل من الحماية الدائمة لأنها تعمل على زيادة قوة الإستثمار المحلى لإنى أمام الإستثمار الأجنبى (15). وتعمل منظمة التجارة العالمية كمنتى للمراجعة الدروية للسياسات التجارية للدول

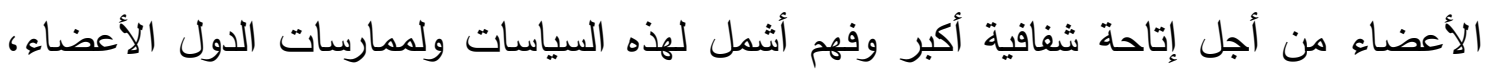

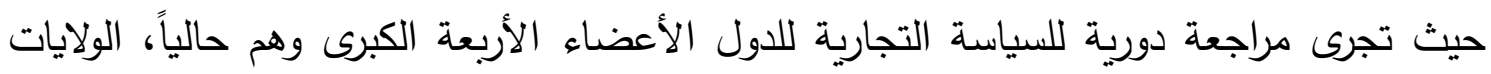

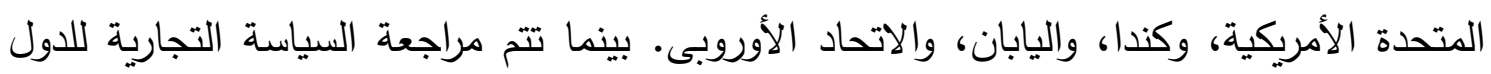

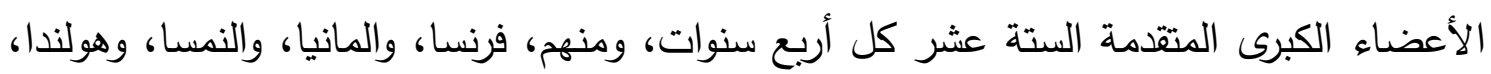

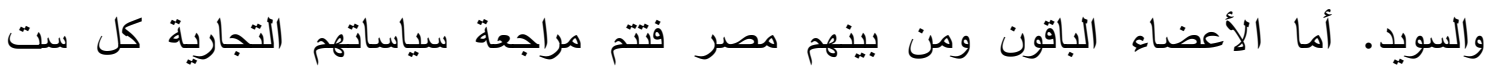
سنوات(16). وقد تمت المراجعة الأولى عند إنضمام مصر إلى المنظمة، ثم المراجعة الثانية لسياسة

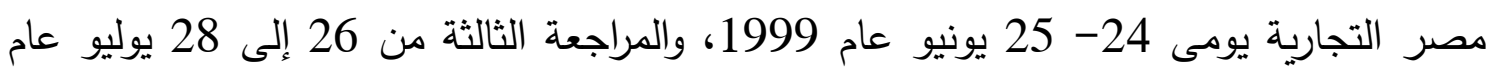


2005، ثم المراجعة المقررة من 26 إلى 28 يوليو عام 2011 ولكنها توقفت نتيجة الثورة

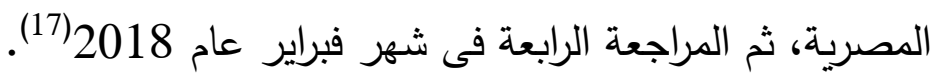

وتشمل عملية مراجعة السياسة التجارية على تقديم سكرتارية منظمة التجارة العالمية تقرير

منفصل حول السياسات التجارية للدولة العضو، بجانب عرض الحكومة لتقريرها حول سياساتها

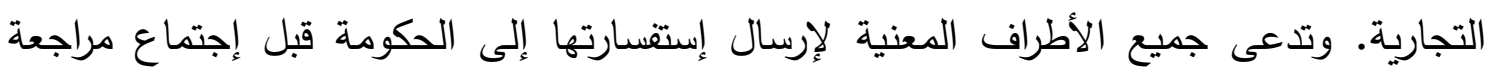

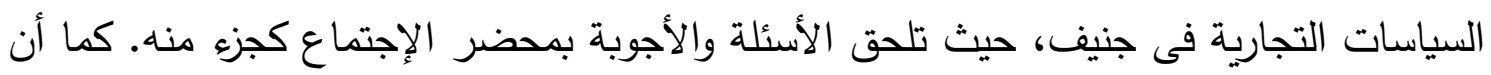
المراجعة تأتى فى إطار إلتزامات الدولة العضو فى منظمة التجارة العالمية، وتهدف إلى تعزيز مبدأ الثفافية وإتاحة الفرصة للدول الأعضاء بالمنظمة لعرض أهم الإصلاحات الاقتصادية والسياسات

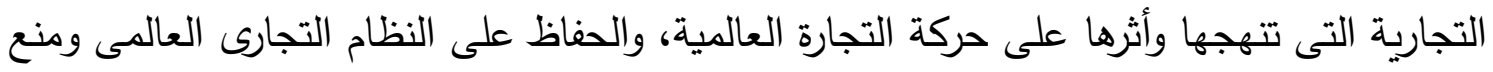
الممارسات الحمائية غير العادلة فى التجارة الدولية.

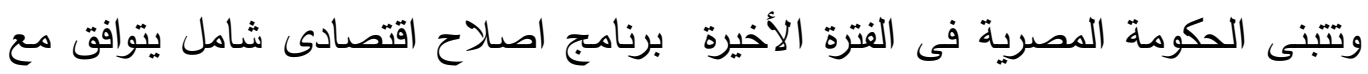
إستراتيجية التتمية المستدامة رؤية مصر 2030، والتى تضع الملف الاقتصادى فى مقدمة

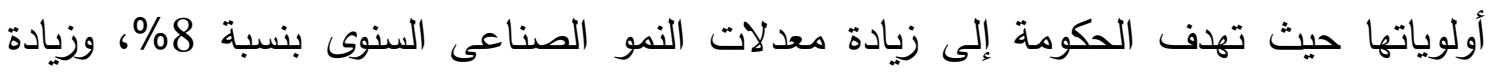

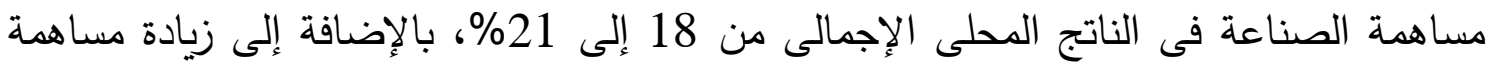
المشروعات المتتاهية الصغر والصغيرة والمتوسطة فى الناتج المحلى الإجمالى بنسبة 10\%،

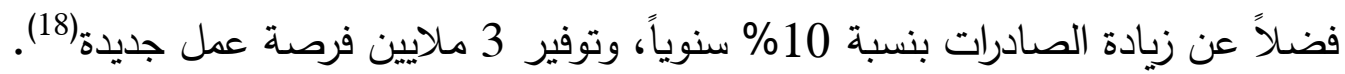
ثالثاً: إنعكاسات السياسات التجارية على تطور الصادرات والواردات المصرية

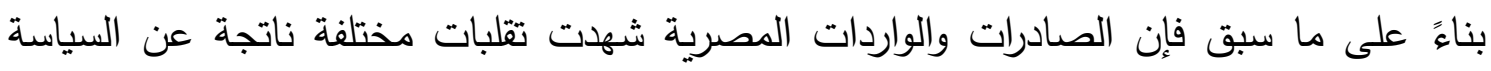

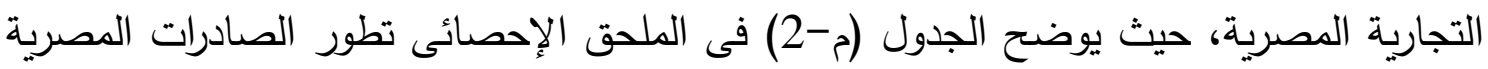

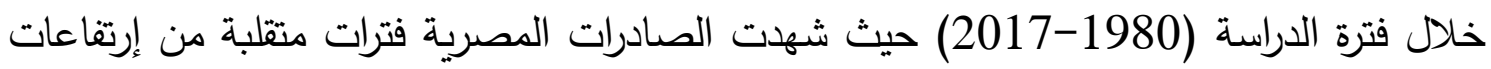
وإنخفاضات، حيث شهدت الثمانينيات فترة الخروج من الحماية الكاملة إلى فترة الحماية الجزئية حيث بلغت إجمالى الصادرات 6.991 مليار دولار فى عام 1980، ثم شهدت إرتفاعات محدودة

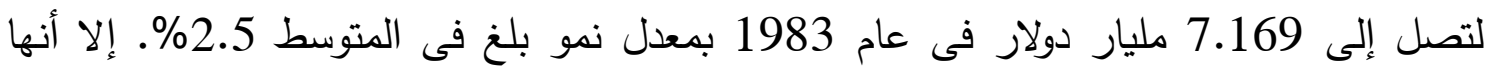


شهدت إنخفاضاً فى عام 1987 حيث بلغت 5.87 مليار دولار . يلى ذلك إرتفاع ملحوظ فى الهى الصادرات لتبلغ مع بداية الإصلاح الاقتصادى فى مصر فى أولى أوائل التسعينات 10.283 مليار

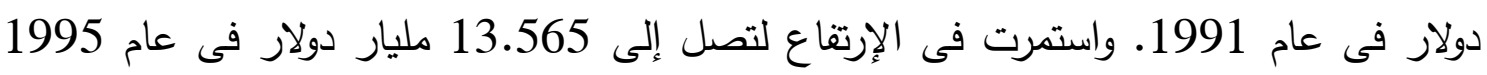

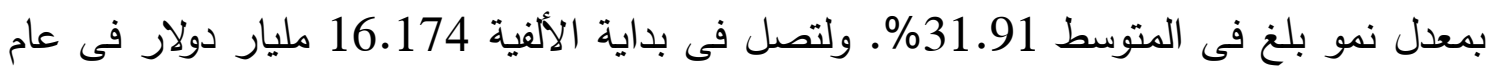

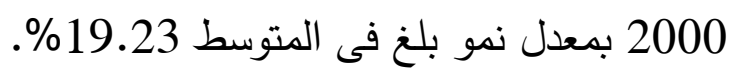
ومع إستمرار عقد الإتفاقيات التجارية التى تعمل على خفض القيط القيود الجمركية مثل الشراكة

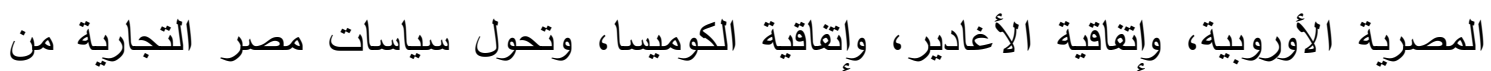

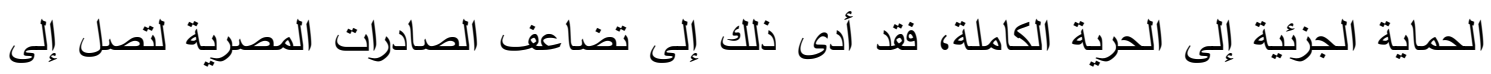

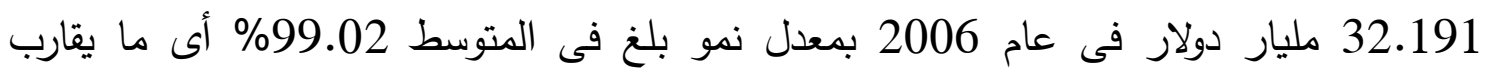

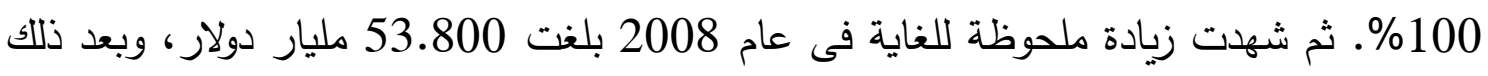

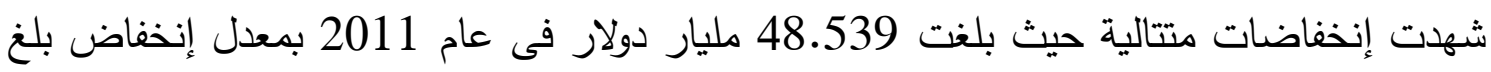
فى المتوسط 9.77 \%. واستمرت الإنخفاضات لتصل فى نهاية فترة الدراسة 38.364 مليار

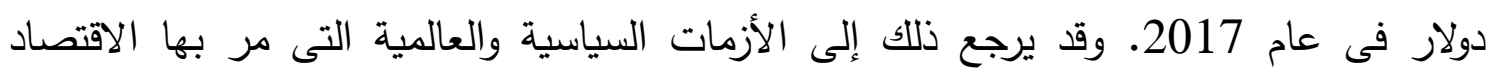

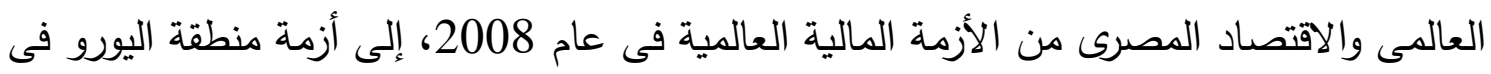
عام 2009، والذى يعتبر الثريك التجارى الأول لمصر مروراً بالثورة المصرية فى عام 2011

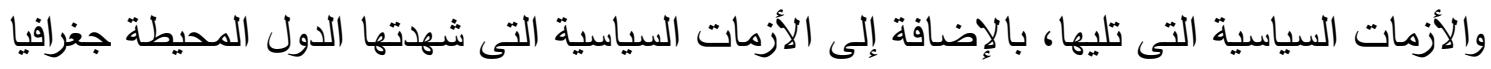

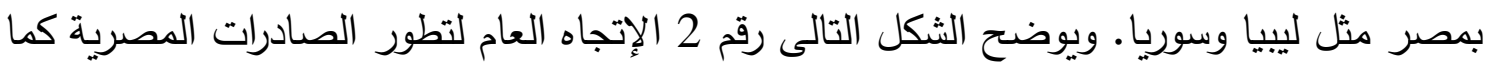

تم تحليلها.

كما يوضح جدول (م-3) فى الملحق الإحصائى تطور الواردات المصرية خلال فترة

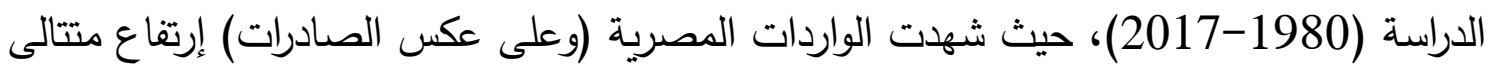
خلال فترة الدراسة بداية من الثمانينيات والتى تعتبر مرحلة الحماية الجزئية حيث بلغت الواردات

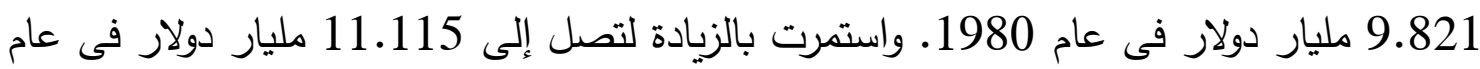
1985 بمعدل نمو بلغ فى المتوسط دمائ 13.17\% 


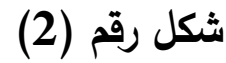

تطور إجمالى الصادرات فى مصر خلال الفترة (1980-2017) بالمليار دولار

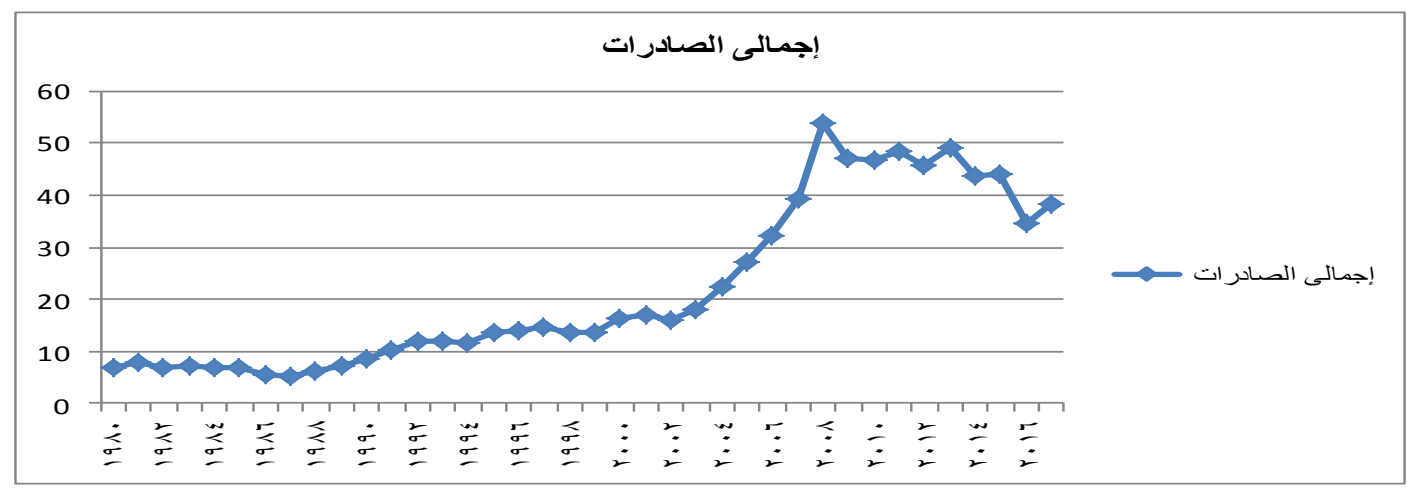

المصدر : .www.worldbank/data.org.

ثم إنخفضت الواردات لمدة عامين متتالين لتصل إلى 9.183 مليار دولار و 9.222 مليار دولار فى عامى 1986 و 1987 على التوالى. ثم يلى ذلك عدة إرتفاعات بلغت 14.106 مليار

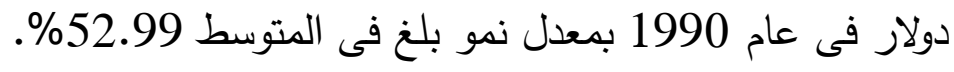

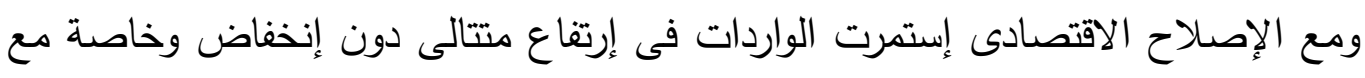

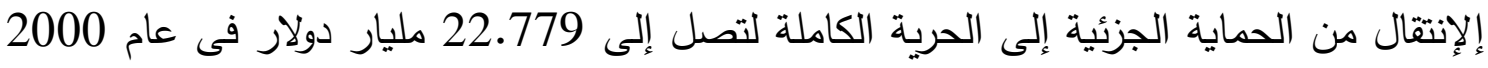

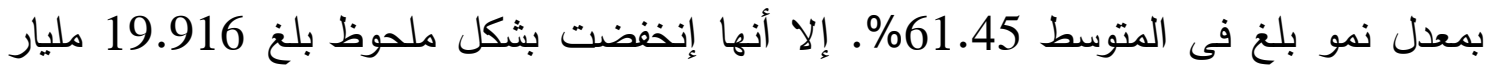

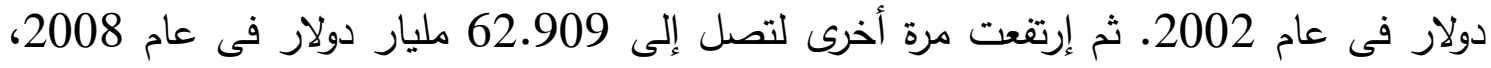

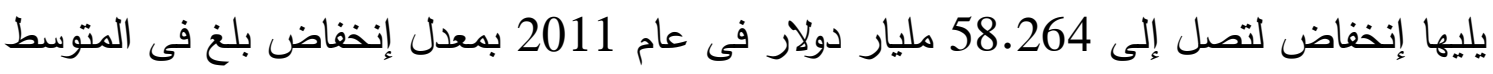

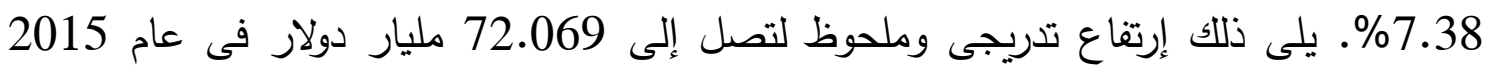
بمعدل نمو بلغ فى المتوسط 23.693\%، وقد يرجع ذللك لكافة الإضطرابات السياسية التى شهدتها

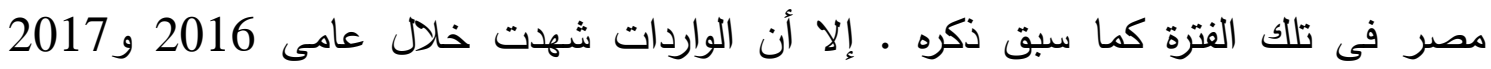
إنخفاضاً بلغ 65.506 مليار دولار و 67.049 مليار دولار على التوالى، وقد يعود ذلك لكات لبداية إستقرار الأوضاع الاقتصادية والسياسية فى مصر. • ويوضح الثكل التالى رقم 3 الإتجاه العام

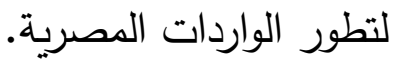




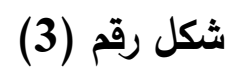

تطور اجمالى الورادات المصرية خلال الفترة (1980-2017) بالمليار دولار

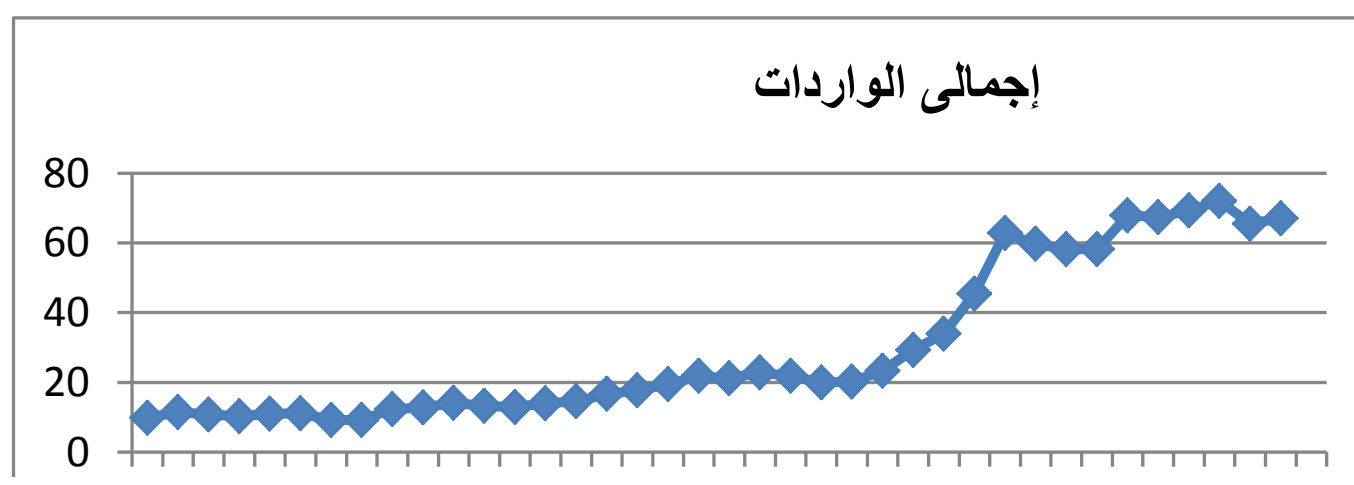

المصدر : . www.worldbank/data.org

رابعاً : البطالة فى الفكر الاقتصادى : .

تعتبر البطالة من أخطر المشكلات الاقتصادية التي تواجه الدول، خاصة الدول النامية

مما جعل البطالة دن أهم الأهداف الاقتصادية التى يعمل صانع القرار على وضع خطة دن السياسات الاقتصادية، وخاصة التجارية لعلاجها وتلافي أثارها السلبية. ولقد إختلف الفكر الاقتصادى فى تفسير أسباب ظهور البطالة، فأنصب تحليل المدرسة الكلاسيكية للبطالة في الأجل الطويل، لوجود إرتباط بين البطالة والمشكلة السكانية، بالإضافة إلي تأثيرها على تراكم رأس المال والنمو الاقتصادي. فمع زيادة معدلات البطالة تتخفض المدخرات وينخفض التراكم الرأسمالي، وبالإعتماد على فرض تساوي الإدخار مع الإستثمار ينخفض النمو الاقتصادي. ويعتبر السبب الرئيسى لظهور البطالة فى المدرسة الكلاسيكية هو رفض العمال العمل بالأجور السائدة، ومن ثم يزداد عرض العمل عن الطلب على العمل في السوق، وهذا يؤدي بدوره إلي تنافس العمال على فرص التوظف، مما يجعلهم يقبلون بأجور أقل، وتلك الأجور المنخفضة تؤدي إلي إنخفاض تكاليف الإنتاج ومن ثم زيادة الأرباح. وهذه الزيادة في الأرباح تحفز أصحاب المشروعات على زيادة الإنتاج وزيادة الطلب على العمال إلي أن تختفي البطالة بين العمال، ويتحقق التوظف الكامل ومن ثم يتمثل علاج البطالة عند الكلاسيك في مرونة الأجور والأسعار وإستجابتها لتغيرات العرض والطلب في سوق المنافسة الكاملة دون تدخل من الدولة أو أي قوي خارجية مثل نقابات العمال التي تمنع إنخفاض الأجور (19). 
مع ملاحظة أن الكلاسيك لم يستبعدوا فكرة ظهور البطالة الإختيارية أو البطالة الجزئية

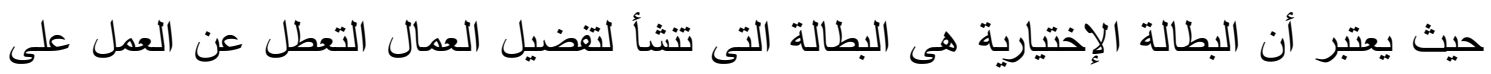

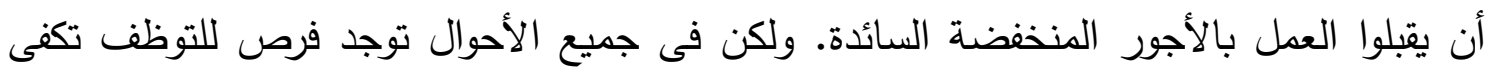

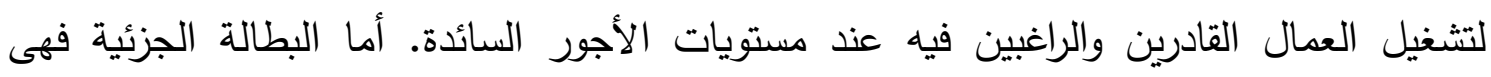

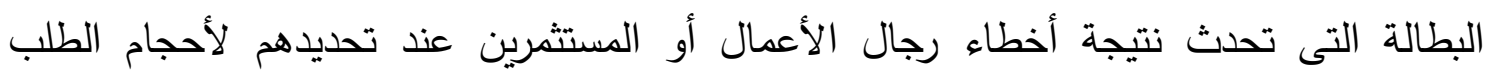
والإنتاج أو لتغير أذواق المستهلكين، ومع ذلك فقد أعتقد الكلاسيك أن البطالة الجزئية التى تتعكس الته

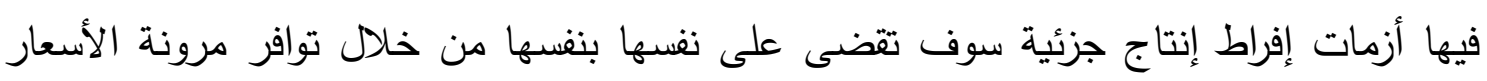
والأجور (20). أما المدرسة الكينزية فلم تعترف بحالة التوظف الكامل لكافة عوامل الإنتاج التي بُني عليها

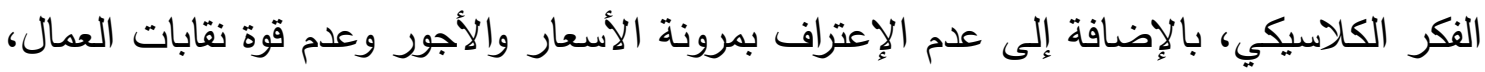
حيث وضح كينز أن تلك الفروض التى قام عليها الفكر الكلايسكى لا تمثل العالم الواقعى فالعمال

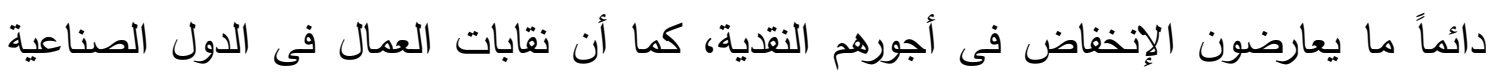

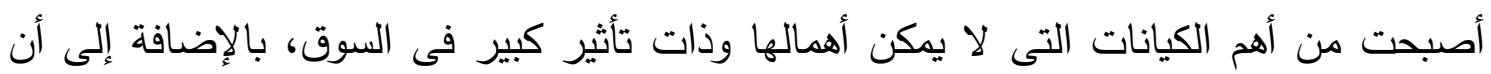

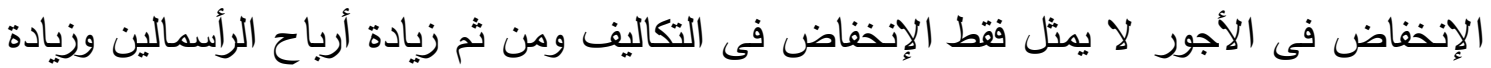

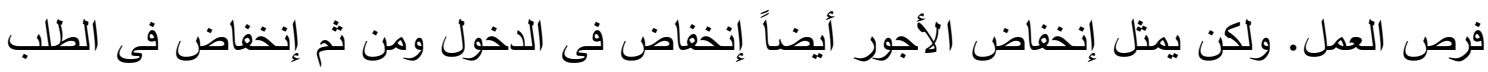

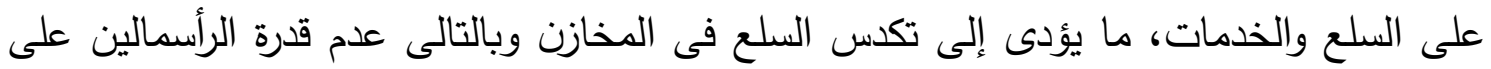

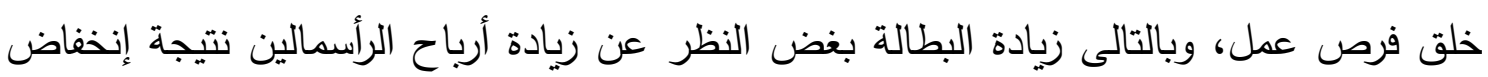

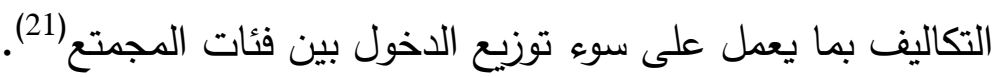
كذلك فإن كينز أكد أن الطلب الكلى الفعال هو الذى يحدد العرض لئ الكات الكلى وليس العكس

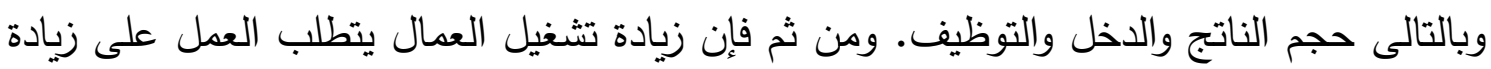

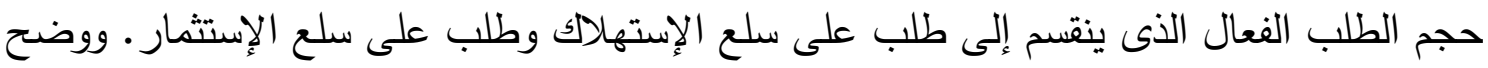

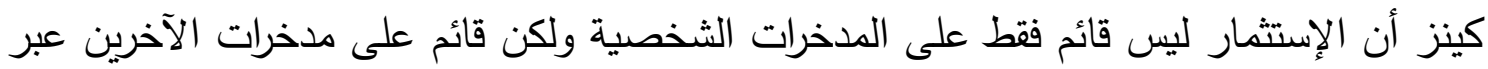

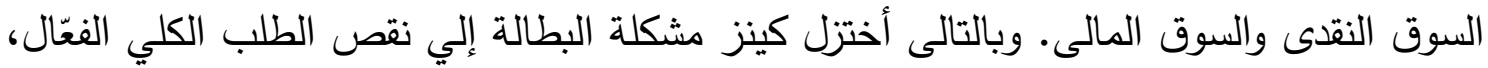


كما أن عدم توازن الإدخار مع الإستثمار هو أمر من المككن أن يسبب تتاقص معدل الربح نتيجة

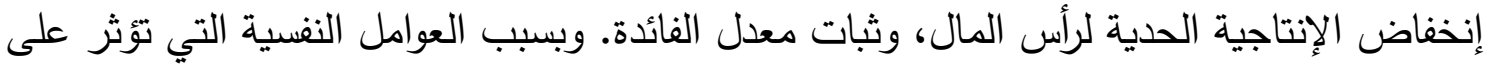

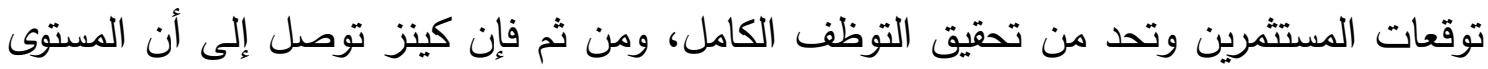

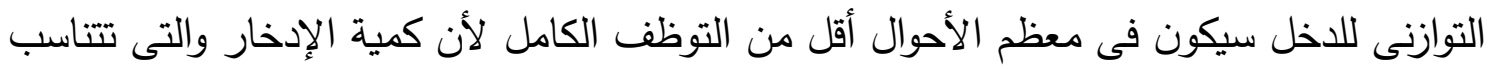

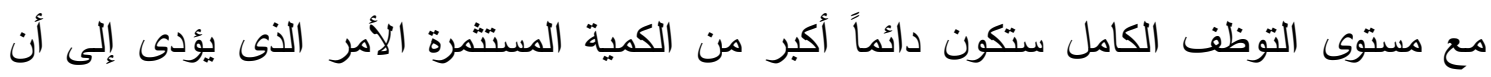
الاقتصاد محكوم عليه بالأزمات والبطالة.

لهذا دعي كينز إلي التدخل فى الشئون الاقتصادية من قبل الدولة أو الحكومة لما لها من

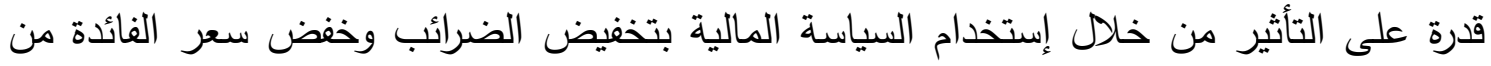

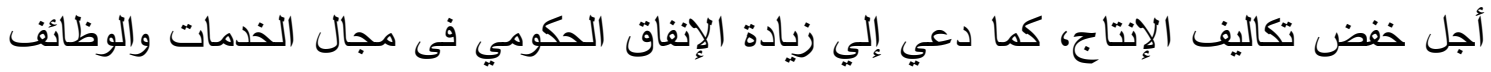

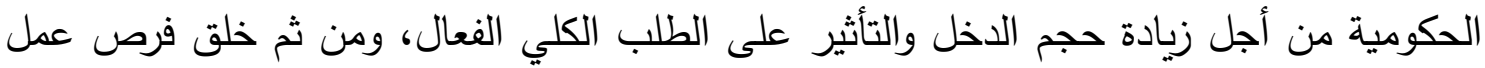

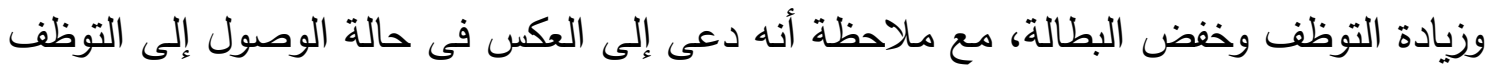
الكامل وظهور التضخم فلابد من خفض حجم الطلب الكلى الفعال (22). أما المدرسة النقدية فاعتبرت النقود هي العامل الرئيسي الذي لهن له الأهمية في الثئون

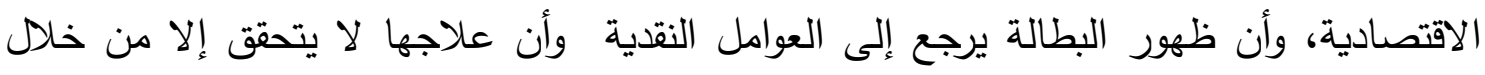

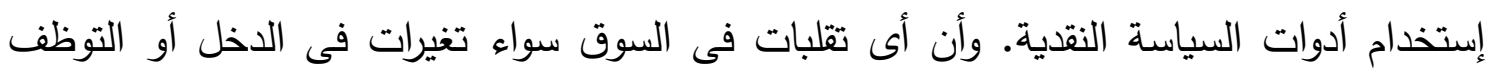
يرجع إلى تدخل الدولة فى آليات السوق أو أخطاء فى إستخدام السياسة النقدية.

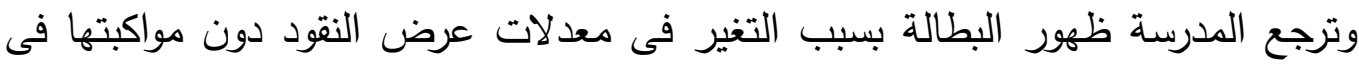

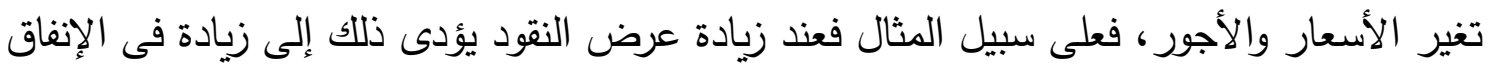

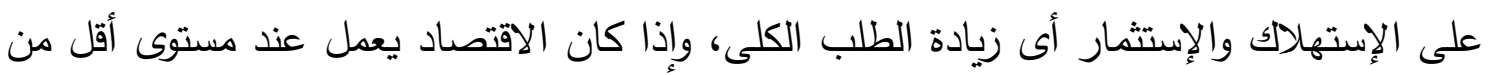

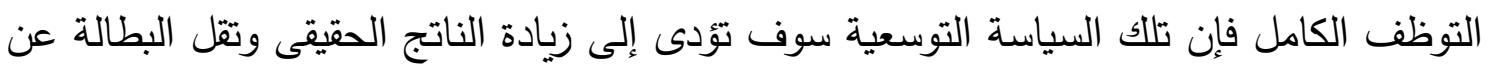

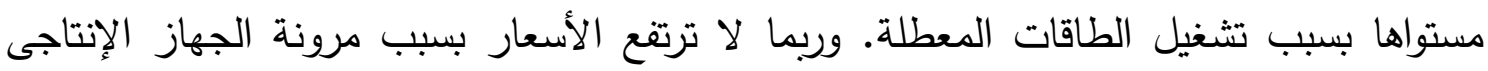

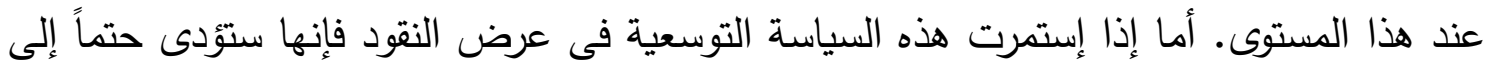

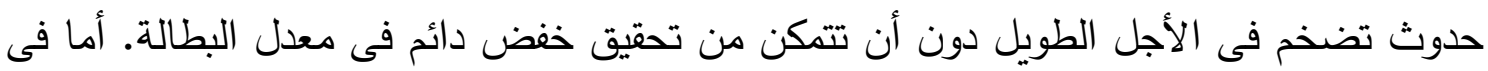
الحالة العكسية عند إنخفاض عرض النقود فإن تلك السياسة الإنكماشية تعمل على خفض الطف الطلب 
على الإستهلاك والإستثمار ومن خفض فى الطلب الكلى إلا أن قدرة الأسعار على التكيف

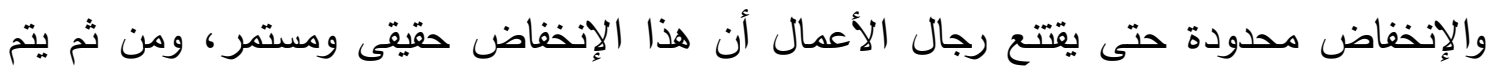

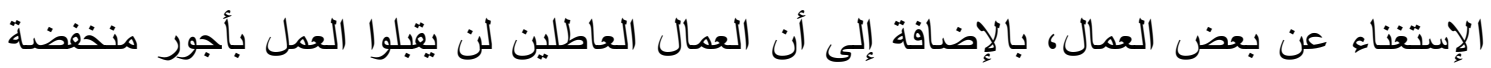
مما يؤدى لزيادة فترة البطالة(23).

لاللك قد تطول فترة الإنكماش والبطالة لعدم مرونة تكيف الأسعار والأجور مع عدم قبول

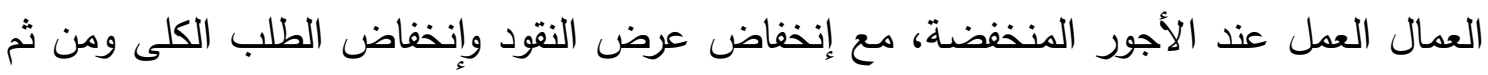
المزيد من البطالة والإنكماش النقدى، بالإضافة إلي سياسات الحكومة التي تعمل على تقديم

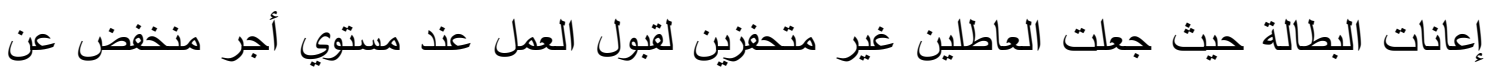
المبلغ التي تمنحه الحكومة في إعانات البطالة(24). بجانب ذللك فلابد من وجود قدر من البطالة يسمي بالمعدل الطبيعي للبطالة، وهي معدل

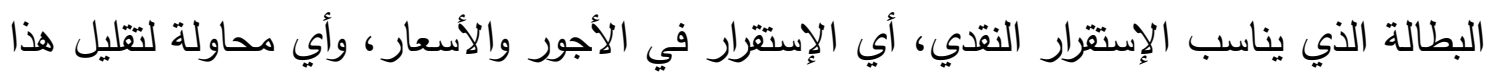

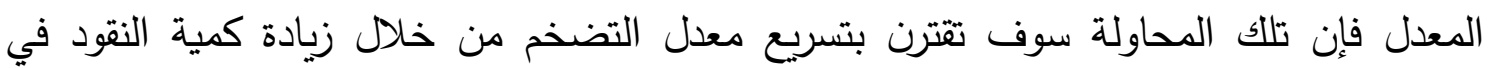

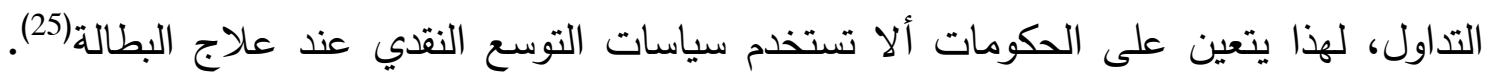

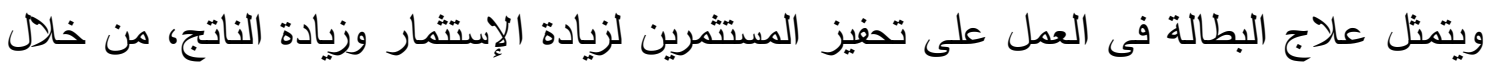

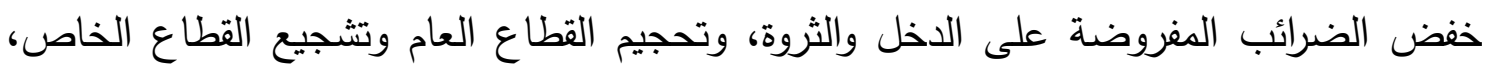
وعدم تقييد آليات السوق ومحاربة الرقابة الحكومية على الأجور والأسعار (26).

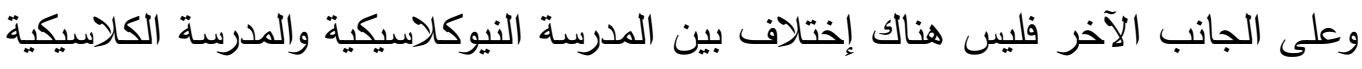

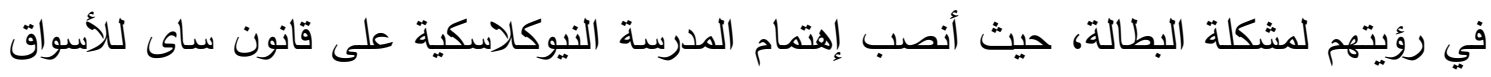

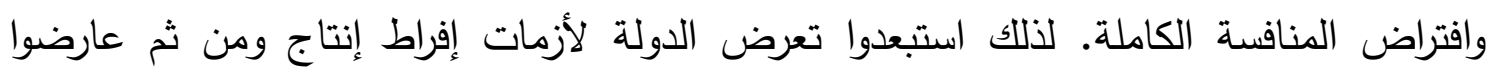

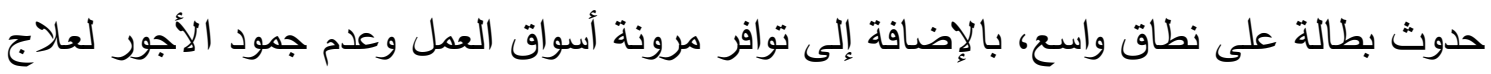

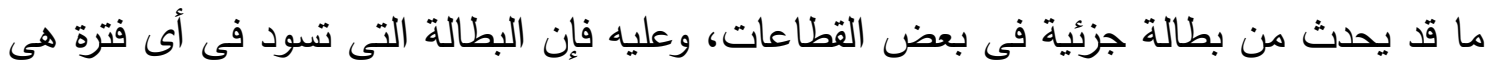

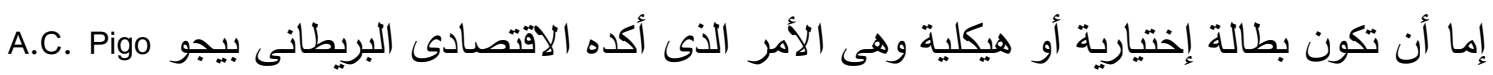
فى كتابه نظرية البطالة فى عام 1993 (27). 
لهذا كان النيوكلاسكيك يعتقدون أن النظام دائماً يدفع نحو تحقيق التوظف الكامل بإستثناء الفترات التى تحدث فيها كوارث طبيعية أو حروب أو إضطرابات نقدية شديدة، ومن ثم فإن النيوكان النيوكلاسيك

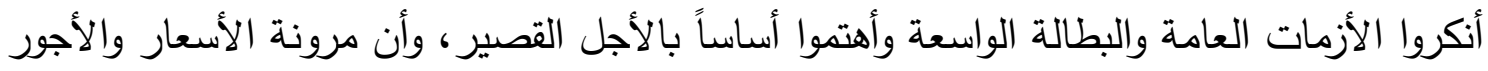
كفيلة بتصحيح الإختلالات في سوق العمل، وتلافي وعلاج البطالة(28). وبالنسبة لمدرسة الكينزيون المحدثون، تم التحول من المنظور قصير الأجل في تحليل

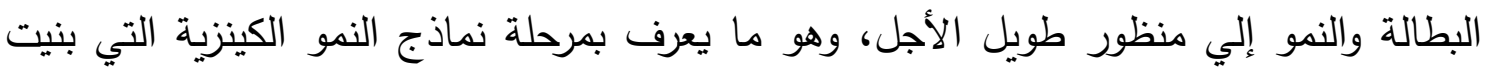

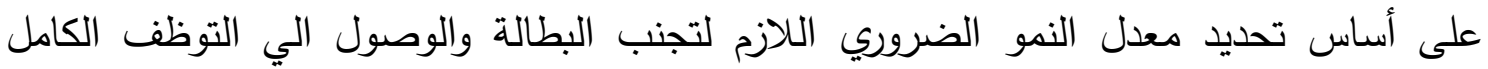
للموارد الاقتصادية. ووصل فكر الكينزيون المحثثون إلي نفس نتيجة الفكر الكينزي من حيث

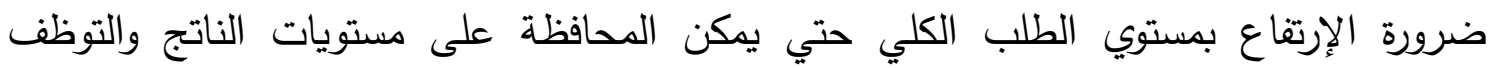

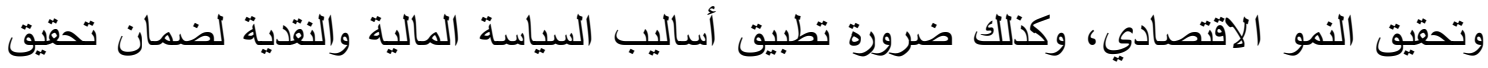
هذا الهدف والتركيز على إعادة توزيع الدخل القومي بين الموارد الاقتصادية لتلافي أزمات الركود

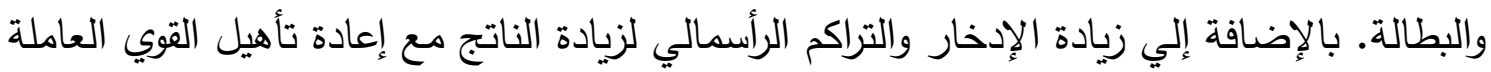
من خلال برامج تدريب لخلق عمالة ماهرة تتوائم مع فرص العمل (29). خامساً : توصيف النموذج القياسى تران تستخدم الدراسة نموذج إنحدار خطي متعدد لإختبار تأثير السياسة التجارية على معدل البطالة فى مصر خلال فترة الدراسة (1980-2017). ويتم التعبير عن السياسة التجارية تلائية بالإيرادات الضريبية المتحصل عليها من التجارة الدولية نسبة من إجمالى الإيراد الكلى، بالإضافة

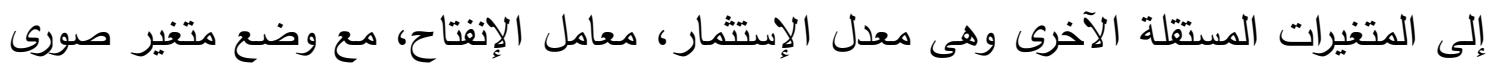

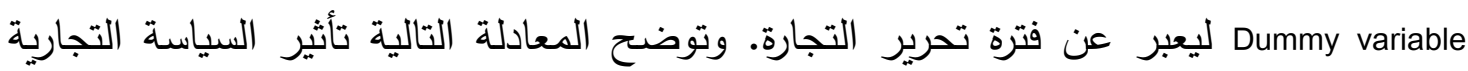
والمتغيرات التنسيرية الأخرى على معدل البطالة فى مصر . $\mathrm{U}_{\text {it }}=\mathrm{C}_{0}+\mathrm{C}_{1} \mathrm{I}_{\mathrm{it}}+\mathrm{C}_{2} \mathrm{TF}_{\mathrm{it}}+\mathrm{C}_{3} \mathrm{TIT}_{\mathrm{it}}+\mathrm{C}_{4} \mathrm{~F}_{\mathrm{it}}+\mathrm{c}_{5} \mathrm{~L}_{\mathrm{it}}$

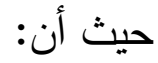

$$
\begin{aligned}
& \text { الدولة مصر محل الدراسة. i } \\
& \text { t عدد سنوات الدراسة وهي (1980-2017). }
\end{aligned}
$$


U = المتغير التابع ويمثل معدل البطالة مصر، وهو عبارة عن نسبة العاطلين من إجمالى القوة العاملة\%\% I = معدل الإستثمار ، وهو نسبة من الناتج المحلى الإجمالى. = معامل الإنفتاح ، وهو حاصل قسمة مجموع الصادرات والواردات على الناتج المحلى TF الإجمالى - المالى = TIT F (1980-1994)، ووضع رقم واحد لفترة الحرية (1995-2017). . L

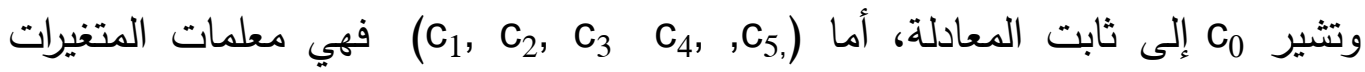
المستقلة. أما التأثير المتوقع للمتغيرات المستقلة على المتغير التابع (معدل البطالة)، بالنسبة لمعدل نمو الإستثار (ا) فإن هناك تأثير سالب لمعدل الإستثمار على معدل البطالة، فعند زيادة الإستثمار، يؤدى ذلك لزيادة المشروعات الإستثمارية ومن ثم زيادة فرص العمل المتاحة، وبالتالى إنخفاض إِ

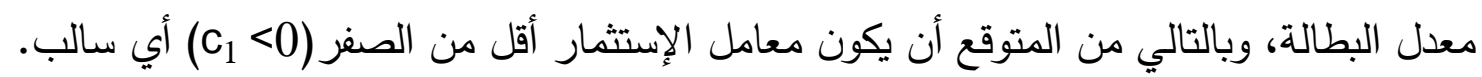
أما تأثير معامل الإنفتاح التجارة (TF) على معدل البطالة بصفة عامة فهو سالب، حيث أن إرتفاع المعامل يعتبر نتيجة زيادة القوة العمل ومن زيادة الناتج المحلى الإجمالى ومن ثم خفض مُ معدل البطالة. ولكن بصفة خاصة وبالنسبة للدول النامية ومنها مصر فإن معامل الإنفتاح يعمل على زيادة معدل البطالة حيث الإنفتاح يترتب عليه فقط عدد من الوظائف للدول التى لديها ميزة تتافسية فى عدد قليل من الصناعات كما هو الحال فى مصر، ومن ثم من المتوقع أن يكون

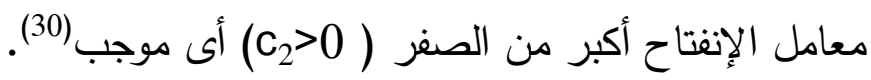
وفيما يتعلق بتأثير الإيرادات الضريبية من التجارة الدولية (TIT) على معدل البطالة، فمن المتوقع أن يكون معامل الإيرادات الضريبية من التجارة الدولية أقل من صفر (c) > c أى سالب. 
حيث تعبر الإيرادات عن إتجاه السياسة التجارية فكلما كانت السياسة تتجه إلى الحريـة كلما يتم خلق فرص عمل وخفض معدل البطالة. أما التأثير المتوقع لحرية التجارة (F) على معدل البطالة فهو سالب، حيث يترتب على إرتفاع حرية التجارة فتح الأسواق الدولية أمام المنتجات المصرية ومن ثم زيادة المشروعات الإستثمارية وزيادة خلق فرص العمل، وزيادة الناتج المحلى الإجمالى ومن ثم خفض معدل البطالة، لذلك من المتوقع أن يكون معامل حرية التجارة أقل من الصفر

$$
\text { . }
$$

\section{5}

تستخدم الدراسة الحالية بيانات السلسلة الزمنية Time Series Data في القياس، لذلك

فقبل تقدير النموذج هنالك عدد من الإختبارات العملية لتحديد طريقة القياس، وهي: - إختبار جذر الوحدة حيث يتم إستخدام إختبار جذر الوحدة Augmented Dickey Fuller Unit Root Test

البيانات. وتم وضع نتائج هذا الإختبار في الجدول (1).

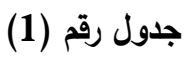

نتائج إختبار جذر الوحدة لمتغيرات نموذج تقدير أثر السياسة التجارية

على معدل البطالة فى مصر (1980-2017)

\begin{tabular}{|c|c|c|}
\hline المتغيرات & اختبار ADF الإحصائي & المعنوية \\
\hline I & $* 4.562-$ & 0.004 \\
\hline $\mathrm{TF}$ & $3.830^{-}$ & 0.026 \\
\hline TIT & $* 6.657-$ & 0.000 \\
\hline$U$ & $3.656^{-}$ & 0.039 \\
\hline
\end{tabular}

* مستقرة عند المستوي الأول للفروق.

وتشير النتائج إلي إستقرار متغيرات معامل الإنفتاح ومعدل البطالة عند المستوى الصفرى،

وإستقرار متغيرات الإيرادات الضرببية ومعدل الإستثمار عند المستوى الأول للفروق، بإستخدام

الثابت Intercept والإتجاه Trend وفترة إبطاء واحدة.

كذلك قبل تقدير النموذج لابد من التأكد من عدم وجود مشكلة الإرتباط المتعدد بين المتغيرات الكلية المستخدمة في النموذج. ويقصد بالإرتباط المتعدد (Multicollinerarity) وجود علاقة 
إرتباط بين أحد المتغيرات المستقلة ومتغير أو أكثر من المتغيرات المستقلة الأخري، مما يؤثر على دقة المعلمات المقدرة. وتم التأكد من عدم وجود إرتباط متعدد من خلال عدد طرق منها حساب الإرتباط Correlation من خلال البرنامج Eviews. ويبين جدول (2) نتائج الإختبار:

\section{جدول رقم (2)}

نتائج إختبار الارتباط المتعدد لتقدير نموذج أثر السياسة التجارية على معدل البطالة في مصر (1980-2017)

\begin{tabular}{|c|c|c|c|}
\hline Variable & I & TIT & TF \\
\hline I & // & 0.639 & 0.207 \\
\hline TIT & 0.639 & $/ /$ & 0.067 \\
\hline TF & 0.207 & 0.067 & $/ /$ \\
\hline
\end{tabular}

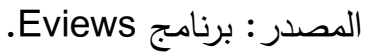

ويتضح من الجدول عدم وجود إرتباط خطي متعدد بين أحد المتغيرات المستقلة ومتغير أو أكثر من المتغيرات المستقلة الأخري في النموذج. كذلك التأكد من عدم وجود مشكلة التباين Hetroskedasticity من خلال إستخدام إختبار White Test لو قيمة الإحتمال أقل من 0.05 يدل على وجود مشكلة التباين. ويبين جدول (3) نتائج الإختبار :

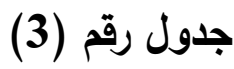

Hetroskedasticity لمشكلة التباين White Test لختبار

\begin{tabular}{|c|c|c|c|}
\hline F- Statistic & 0.668 & Prob. F(9.28) & 0.730 \\
\hline Obs R-Squared & 6.717 & Prob. Chi-Square(9) & 0.666 \\
\hline Scaled Explained SS & 3.514 & Prob.Chi-Square(9) & 0.940 \\
\hline
\end{tabular}

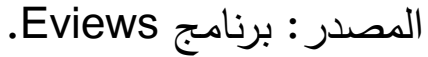


ويتضح من الجدول عدم وجود مشكلة التباين حيث بلغ قيمة الإحتمال أكبر من 0.05. 2.5

تستخدم الدراسة الحالية بيانات السلسلة الزمنية Time Series data لمصر خلال الفترة (1980-2017)، من خلال إستخدام نموذج إنحدار خطي متعدد لإختبار تأثير السياسة التجارية على معدل البطالة فى مصر . هذا وقد تم تجميع بيانات المتغيرات عن الفترة (1980- 2017) من مصدر بيانات صندوق النقد الدولى من الموقع الإلكتروني لنسي البنك الدولى www.Worldbankldata.org. وظهر فى نتائج قياس المعادلة مشكلة الإرتباط الذاتى بين قيم حد الخطأ عبر الزمن وذلك الك من خلال إختبار ديرين وتسون Durbin-Waston حيث بلغ قيمة D.W (0.99)، ولعلاج تلك

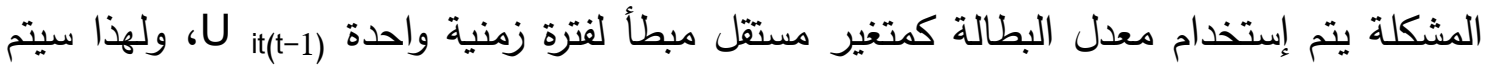
تقدير معادلة معدل البطالة كالتالى:

(2) $\mathrm{U}_{\mathrm{it}}=\mathrm{c}_{0}+\mathrm{C}_{1} \mathrm{I}_{\mathrm{it}}+\mathrm{C}_{2} \mathrm{TF}_{\mathrm{it}}+\mathrm{C}_{3} \mathrm{TIT}_{\mathrm{it}}+\mathrm{C}_{4} \mathrm{~F}_{\mathrm{it}}+\mathrm{C}_{5} \mathrm{U}_{\mathrm{it}(\mathrm{t}-1)}+\mathrm{c}_{6} \mathrm{~L}_{\mathrm{it}}$ ويقدم جدول (4) نتائج تقدير نموذج أثر السياسة التجارية على معدل البطالة فى مصر (1980.(2017

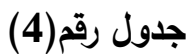

نتائج تقدير نموذج أثر السياسة التجارية على معدل البطالة

فى مصر خلال الفترة (1980-2017)

\begin{tabular}{|c|c|c|c|}
\hline المتغيرات & قيمة المعلمات Coefficient & T-Statistic & المعنوية \\
\hline C & 9.372 & 4.165 & 0.000 \\
\hline I & $0.120^{-}$ & $2.879-$ & 0.007 \\
\hline $\mathrm{TF}$ & 0.497 & 0.444 & 0.656 \\
\hline TIT & $0.150^{-}$ & $2.939-$ & 0.006 \\
\hline $\mathrm{F}$ & $0.171-$ & $0.425^{-}$ & 0.673 \\
\hline $\mathrm{U}(-1)$ & 0.426 & 2.865 & 0.007 \\
\hline $\mathrm{R}^{2}$ & 0.890 & & \\
\hline Adjusted- $R^{2}$ & 0.872 & & \\
\hline F-Statistic & 50.384 & & 0.000 \\
\hline D.W & 1.50 & & \\
\hline
\end{tabular}

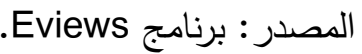


تشير نتائج التقدير في جدول (4) أن قيمة معامل التحديد المعدل R ملغ (0.89)، وهذا يعني أن المتغيرات المستقلة تفسر (89\%) من التغيرات في معدل البطالة فى مصر • وأن قيمة إختبار F الإحصائي يدل على أن النموذج جيد وقدرته التفسيرية عالية، وأن المتغيرات المستقلة مجتمعة لها تأثير معنوي على معدل البطالة خلال فترة الدراسة (1980-2017). وفيما يتعلق بتأثير المتغيرات التفسيرية على معدل البطالة، فإن التقديرات تشير إلي أن إشارات معاملات المتغيرات التفسيرية تتقق مع تلك المتوقعة عند التوصيف النظري للنموذج. حيث بلغ التأثير السلبي لمعامل الإستثمار (0.120) وهذا يعنى أنه عند زيادة الإستثمار بنسبة 1\% يؤدى ذلك إلى خفض معدل البطالة بنسبة 120\%، كما أن تأثير الإستثمار معنوى إحصائياً عند مستوى 1\%. كما توضح التقديرات التأثير الإيجابى لمعامل الإنفتاح حيث بلغ معامل الإنفتاح (0.497) وهذا يعنى أنه عند زيادة الإنفتاح بنسبة 1\% يؤدى إلى زيادة معدل البطالة بنسبة 0.497\%، مع العلم أن تأثير الإنفتاح على معدل البطالة غير معنوى إحصائياً. كذلك توضح التقديرات التأثير السلبى لإجمالى الإيرادات الضرببية على التجارة الدولية نسبة من الإيراد الكلى على معدل البطالة حيث بلغ معامل الإيرادات الضريبية (0.150)، وهذا يعني أن زيادة الإيرادات الضريبية على التجارة الدولية بنسبة 1\% يؤدي إلي خفض معدل البطالة بنسبة 0.150\%. كما أن تأثير الإيرادات الضريبية على معدل البطالة معنوي إحصائياً عند مستوي 1\%. وفيما يتعلق بمعامل حرية التجارة فتثير التقديرات إلي وجود تأثير سلبى لمعامل حرية التجارة على معدل البطالة، بلغ (0.171). وهذا يعني أنه عند زيادة الحرية بنسبة 1\% يؤدي إلي خفض معدل البطالة بنسبة 0.171\%. مع العلم أن هذا التأثير غير معنوي إحصائياً. وتثير النتائج السابقة للنموذج القياسى إلى تأثير السياسة التجارية فى مصر على معدل البطالة بداية من الحماية الجزئية إنتقالًا إلى الحرية، وعقد المزيد من الإتفاقيات والترتيبات التجارية التى تعمل على خلق فرص عمل وزيادة الإنتاجية ورفع معدل النمو الاقتصادى. ومن ثم صحة فرضية الدراسة القائمة على "وجود تأثير للسياسة التجارية على معدل البطالة فى مصر ". 


\section{سادساً .الخلاصة والنتائج}

تهدف الدراسة إلى إختبار أثر السياسة التجارية على معدل البطالة فى مصر خلال فترة

الدراسة (1980-2017) بإستخدام نموذج إنحدار خطى متعدد مع إستخدام بيانات السلسلة الزمنية. وفى سبيل تحقيق هذا الهدف فقد تضمنت الدراسة أربعة أجزاء بخلاف المقدمة، حيث تعرض الجزء الثانى بإختصار إلى السياسة التجارية فى الفكر الاقتصادى. ثم تم عرض السياسة التجارية فى مصر بإختصار بداية من إتباع إستراتيجية ذات التوجه الداخلى المعتمد على الإحلال محل الواردات، وفرض قيود جمركية لحماية الصناعة المحلية وحماية فرص العمل، إنتقالاً إلى الى مرحلة الإستراتيجية ذات التوجه الخارجى بإستخدام سياسة الإنتاج من أجل التصدير ، وإلغاء القيود الجمركية المفروضة على الواردات وفتح الأسواق أمام المنتجات الأجنبية، بالإضافة إلى توضيح الجزء الثانى لأثر إتجاه السياسة التجارية فى مصر على التجارة المصرية من خلال تحليل كل من معدل التعريفة الجمركية وإجمالى الصادرات والورادات المصرية فى فترة الدراسة. كما تناولت الدراسة فى الجزء الثالث البطالة فى الفكر الاقتصادى بداية من الفكر الكلاسكى إنتهاءاً بفكر الكينزيون المحدثون.

أما الجزء الرابع فتناول أثر السياسة التجارية على معدل البطالة خلال الفترة (19802017) بإستخدام نموذح إنحدار خطى متعدد بإستخدام البيانات السلسلة الزمنية، وقد أظهرت نتائج النموذج الحقائق التالية : 1. الأثر السلبى لإيرادات الضريبية من التجارة الدولية على معدل البطالة حيث بلغ التأثير السلبي لمعامل الإيرادات الضرببية على معدل البطالة (0.150)، وهذا يعني أن زيادة الإيرادات الضرببية بنسبة 1\% يؤدي إلي خفض معدل البطالة بنسبة 0.150 \% 2. الأثر السلبى لمعدل الإستثمار على معدل البطالة، حيث بلغ معامل الإستثمار (0.120). وهذا يعني أنه عند زيادة الإستثمار بنسبة 1\% يؤدي إلي خفض معدل البطالة بنسبة \%0.120 
3. أن معامل الإنفتاح له تأثير إيجابى على معدل البطالة بلغ (0.497). وهذا يعنى أنه عند زيادة الإنفتاح بنسبة 1\% يؤدى إلى زيادة معدل البطالة بنسبة 0.497\% مع العلم أنه غير معنوى إحصائياً.

4. التأثير السلبى لمعامل حرية التجارة على معدل البطالة حيث بلغ معامل حرية التجارة (0.171). وهذا يعنى عند زيادة حرية التجارة بنسبة 1\% يؤدى إلى خفض معدل البطالة بنسبة 0.171\%، مع العلم أنه غير معنوى إحصائياً. وهكذا فإن النتائج السابقة توضح صحة فرضية الدراسة وهى "تأثير السياسة التجارية على معدل البطالة فى مصر". وإذا أردنا الإستفادة القصوى من سياستنا التجارية فعلى الحكومة المصريـة أن تنفذ مجموعة من التوصيات أهمها:

1. إستكمال تنفيذ كافة الإتفاقيات والمعاهدات الموقعة عليها مصر والإلتزام بكافة بنودها. 2. إختيار المشروعات الإستثمارية التى توفر فرص عمل مناسبة لمهارة العاملين المصريين. 3. زيادة الدورات التدريبية لرفع مهارة العاملين المصريين لتتناسب مع المنافسة الشرسة للعمالة الاجنبية فى الشركات الدولية او متعددة الجنسيات.

لذلك على صانع القرار فى مصر إعادة هيكلة كافة الإتفاقيات والمعاهدات التجارية ونوعية الإستثمارات الأجنبية داخل مصر، لكى يتم الإستفادة أكبر من تلك الإتفاقيات لخلق فرص العمل وخفض معدل البطالة الهدف المرجو تحقيقه. 
(1)-Gozger. G. (2013), The Impact of Trade Openness on The Unemployment Rate in G7 Countries, The Journal of International Trade and Economic Devlopment, Vol. 23, Issue. 7, pp:1018-1037.

(2)-Yanikkaya. H. (2013),Is Trade Liberalization a Solution to The Unemployment Problem?, Portuguese Economic Journal, Vol. 12, Issue. 1, PP: 57-85.

(3) - Nwaka. I, E. Uma and G. Tune. (2015), Trade Openness and Unemployment: Empirical Evidence for Nigeria, The Economic and Labour Relations Review, Vol. 26(1), PP: 117-136. (4) - Warrad. T. (2017), Trade Openness, Economic Growth and Unemployment Reduction in Arab Region, Internatioal Journal of Economics and Financial, Vol.8(1), PP:179-183.

(5)_ Zaki.C, M. Salem. (2017), Revisiting The Impact of Trade Openness on Informal and Irregular Employment in Egypt, with no publisher, PP:1-34.

(6)- غيس، موارى. (2007)، السياسة التجارية، الإستراتيجيات الإنمائية الوطنية مذكرات توجيهية فى السياسات،

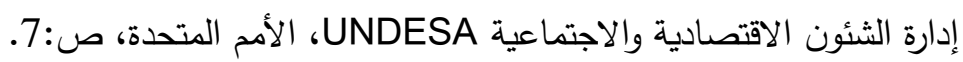

(7) _ Salvatore. D. (1995), International Trade Policies, Industrialization and Economic Developments, MEDIT, No. 4, P: 4.

${ }^{(8)}$ - Sally. R. (2008), Trade Policy, New Century: the WTO, FTAS and Asia Rising, IEA. The Institute of Economic Affairs, PP: 3-5.

(9)- المرزوك، خالد (2014)، السياسات التجارية، الاقتصاد الدولى، كلية الاقتصاد والإدارة، جامعة بابل، ص:

(10)_ Dorobat. C. (2015), A brief History of International Trade Thought: From Pre-Doctrinal Contributions to the $21^{\text {st }}$ Century Heterodox International Economics, the Journal of Philosophical Economics: Reflection on Economic and Social Issues, Vol. viii. Issue. 2, P: 110 .

(11) - Stojanov. D. (2007), Validity of the Economic Thoughts of Keynes and Marx for the $21^{\text {st }}$ Century, Zb.rad.Ekon.fak.RiJ, Vol.25, No. 1, P:16.

$$
\begin{aligned}
& \text { (12)- المرزوك، خالد، مرجع سبق ذكره، ص: } 40 .
\end{aligned}
$$

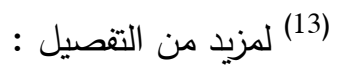


- Martin. W. (2001), Trade Policies, Developing Countries and Globalization, World Bank, PP:14-22.

(14) - John. S. (1990), Understanding International Trade Policies an Emerging Synthesis,

Cambridge University Press, World Politics, Vol.43, No. 1, PP: 140-141.

${ }^{(15)}$ - www.mti.gov.eg.

(16) - Sally. R., op.it, PP: 100-103.

(17) - www.mti.gov.eg.

(18) - www.miic.gov.eg.

(19)- زكي، رمزي. (1998)، الاقتصاد السياسي للبطالة: تحليل لأخطر مشكلات الرأسمالية المعاصرة، سلسلة

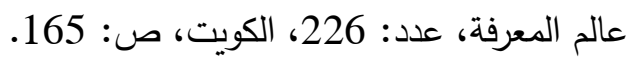

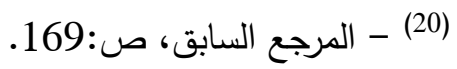
(21) - المرجع السابق، ص:279.

(22)_ Pavlina. R. (2008), Keynes's Approach to Full Employment Aggregate or Targeted Demand?, The Levy Economics Institute of Bard College, Working Paper, No. 542, PP: 6-7.

$$
\text { (23) - زكى، رزى، مرجع سبق ذكره، ص: } 350 .
$$

(24)_ Friedman. M. (1968), The Role of Montery Policy, "American Economic Review", Vol. 58, No. $1, \mathrm{pp}: 2-3$.

(25) - Stuart. E. (1986), The Natural Rate of Unemployment Concepts and Issues, Federal Reserve Bank of Kansas City, Economic Review, p:11.

$$
\text { (26) - زكى، رمزى، مرجع سبق ذكره، ص: } 347 .
$$

(27) _ Pigo. A. (1933), The Theory of Unemployment, Macmillan, London, P:252.

(28) - Jerome. L. (1981), Monetarist, Keynesian, and New Classical Economics, The American Economic Review, Vol. 71, No. 2, p: 139.

(29)_ Gail. J. , F. Smets. And R. Wouters. (2011), Unemployment in an Estimated New Keynesian Model, NBER, Vol. 26, P: 332.

(30) - Ghosh. A, P. Saumik. (With No Data), Opening The Pandora's Box? Trade Openness and Informal Sector Growth, Department of Economics, Claremont Graduate University, USA. 


\section{الملحق الإحصائى}

جدول رقم (م-1) تطور معدل التعريفة عل جميع المنتجات

بالأوساط المرجحة خلال الفترة (1995-2017) \%

\begin{tabular}{|c|c|c|c|}
\hline معدل & (السنة & التعريفة & 1995 \\
\hline 8.92 & 2007 & 17.5 & 1996 \\
\hline 8.02 & 2008 & 16.1 & 1997 \\
\hline 8.26 & 2009 & 16.1 & 1998 \\
\hline 9.71 & 2010 & 14.7 & 1999 \\
\hline 7.71 & 2011 & 16.68 & 2000 \\
\hline 7.47 & 2012 & 16.82 & 2001 \\
\hline 8.55 & 2013 & 16.72 & 2002 \\
\hline 7.43 & 2014 & 19.89 & 2003 \\
\hline 7.08 & 2015 & 15.04 & 2004 \\
\hline 6.63 & 2016 & 10.63 & 2005 \\
\hline 6.85 & 2017 & 8.76 & 2006 \\
\hline
\end{tabular}

المصدر: www.worldbank/data.org 


$$
\text { جدول رقم (م-2) }
$$

تطور الصادرات المصرية خلال الفترة (1980-2017) القيمة بالمليار دولار

\begin{tabular}{|c|c|c|c|}
\hline إجمالى الصادرات & السنة & - ·إجمالى الصادرات & السنة \\
\hline 13.653 & 1999 & 6.991 & 1980 \\
\hline 16.174 & 2000 & 7.810 & 1981 \\
\hline 17.065 & 2001 & 6.918 & 1982 \\
\hline 16.090 & 2002 & 7.169 & 1983 \\
\hline 18.074 & 2003 & 6.849 & 1984 \\
\hline 22.257 & 2004 & 6.908 & 1985 \\
\hline 27.213 & 2005 & 5.644 & 1986 \\
\hline 32.191 & 2006 & 5.087 & 1987 \\
\hline 39.469 & 2007 & 6.069 & 1988 \\
\hline 53.800 & 2008 & 7.094 & 1989 \\
\hline 47.163 & 2009 & 8.646 & 1990 \\
\hline 46.731 & 2010 & 10.283 & 1991 \\
\hline 48.539 & 2011 & 11.885 & 1992 \\
\hline 45.808 & 2012 & 12.034 & 1993 \\
\hline 49.111 & 2013 & 11.714 & 1994 \\
\hline 43.520 & 2014 & 13.565 & 1995 \\
\hline 43.862 & 2015 & 14.033 & 1996 \\
\hline 34.442 & 2016 & 14.778 & 1997 \\
\hline 38.364 & 2017 & 13.754 & 1998 \\
\hline
\end{tabular}

المصدر: www.worldbank/data.org 


$$
\text { جدول رقم (م-3) }
$$

تطور الواردات المصرية خلال الفترة (1980-2017)القيمة بالمليار دولار

\begin{tabular}{|c|c|c|c|}
\hline إجمالى الواردات & السنة & إجمالى الواردات & السنة \\
\hline 21.144 & 1999 & 9.821 & 1980 \\
\hline 22.779 & 2000 & 11.422 & 1981 \\
\hline 21.801 & 2001 & 10.731 & 1982 \\
\hline 19.916 & 2002 & 10.250 & 1983 \\
\hline 20.219 & 2003 & 10.973 & 1984 \\
\hline 23.330 & 2004 & 11.115 & 1985 \\
\hline 29.245 & 2005 & 9.183 & 1986 \\
\hline 33.931 & 2006 & 9.222 & 1987 \\
\hline 45.443 & 2007 & 12.322 & 1988 \\
\hline 62.909 & 2008 & 12.826 & 1989 \\
\hline 59.712 & 2009 & 14.109 & 1990 \\
\hline 58.196 & 2010 & 13.233 & 1991 \\
\hline 58.264 & 2011 & 12.938 & 1992 \\
\hline 67.928 & 2012 & 14.015 & 1993 \\
\hline 67.399 & 2013 & 14.561 & 1994 \\
\hline 69.282 & 2014 & 16.661 & 1995 \\
\hline 72.069 & 2015 & 17.718 & 1996 \\
\hline 65.506 & 2016 & 19.528 & 1997 \\
\hline 67.049 & 2017 & 21.812 & 1998 \\
\hline
\end{tabular}

